YOON et al

\title{
SMAD3 Determines Conventional versus Plasmacytoid Dendritic Cell Fates
}

Running title: SMAD3 determines cDC vs. pDC

Jeong-Hwan Yoon ${ }^{1,2}$, Eunjin Bae ${ }^{1,2}$, Katsuko Sudo ${ }^{3}$, Jin Soo Han ${ }^{4}$, Seok Hee Park ${ }^{5}$,

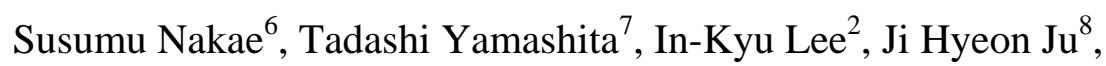

Isao Matsumoto ${ }^{9}$, Takayuki Sumida ${ }^{9}$, Masahiko Kuroda ${ }^{1}, \operatorname{Keiji~Miyazawa~}^{10}$,

Mitsuyasu Kato ${ }^{11} \&$ Mizuko Mamura ${ }^{* 1,2,12}$

${ }^{1}$ Department of Molecular Pathology, Tokyo Medical University, Tokyo, 160-8402, Japan,

${ }^{2}$ Biomedical Research Institute, Kyungpook National University Hospital, Daegu, 41944, Republic of Korea, ${ }^{3}$ Animal Research Center, Tokyo Medical University, Tokyo, 160-8402, Japan, ${ }^{4}$ Institute for the 3Rs, Department of Laboratory Animal Medicine, College of Veterinary Medicine, Konkuk University, Seoul, 05029, Republic of Korea, ${ }^{5}$ Department of Biological Sciences, Sungkyunkwan University, Suwon, 16419, Republic of Korea, ${ }^{6}$ Laboratory of Systems Biology, Center for Experimental Medicine and Systems Biology, The Institute of Medical Science, The University of Tokyo, Tokyo, 108-863, Japan, ${ }^{7}$ Laboratory of Veterinary Biochemistry, Azabu University School of Veterinary Medicine, Sagamihara, 252-5201, Japan, ${ }^{8}$ Department of Rheumatology, Catholic University of Korea, Seoul St. Mary Hospital, Seoul, 06591, Republic of Korea, ${ }^{9}$ Department of Internal Medicine, University of Tsukuba, 305-8575, Tsukuba, Japan, ${ }^{10}$ Departments of Biochemistry, University of Yamanashi, Yamanashi, 409-3898, Japan, ${ }^{11}$ Department of Experimental Pathology, Graduate School of Comprehensive Human Sciences and Faculty of Medicine, University of Tsukuba, Tsukuba, 305-8575, Japan, ${ }^{12}$ Diversity Promotion Center, Tokyo Medical University, Tokyo, 160-8402, Japan

*Correspondence: Mizuko Mamura, M.D., Ph.D.

Department of Molecular Pathology, Diversity Promotion Center, Tokyo Medical University, 6-1-1 Shinjuku, Shinjuku-ku, Tokyo, 160-8402, Japan, TEL: +81-3-3351-6141, FAX: +81-33351-6173, Biomedical Research Institute, Kyungpook National University Hospital, 135

Dongduk-ro Jung-gu, Daegu, 41944, Republic of Korea E-mail: mamumik@ tokyo-med.ac.jp, mikoeyo@gmail.com 
YOON et al

\section{SUMMARY}

Transforming growth factor (TGF)- $\beta$ plays crucial roles in differentiation of dendritic cells (DC). However, molecular mechanisms how TGF- $\beta$ regulates DC differentiation remain largely unknown. Here, we show that selective repression of one of the TGF- $\beta$ receptor-regulated SMADs (R-SMADs), SMAD3 directs conventional DC (cDC) differentiation, whereas maintenance of SMAD3 is indispensable for plasmacytoid DC (pDC) differentiation. Expression of SMAD3 was specifically downregulated in $\mathrm{CD}^{+15^{+}}$ common DC progenitor (CDP), pre-cDCs and cDCs. SMAD3 deficient mice showed a significant reduction in pre-pDCs and pDCs with increased CDP, pre-cDCs and cDCs. SMAD3 upregulated the pDC-related genes: SPI-B, E2-2 and IKAROS, while it repressed FLT3 and the cDC-related genes: IRF4 and ID2. STAT3 and a SMAD transcriptional co-repressor, c-SKI repressed SMAD3 for cDC differentiation, whereas canonical SMAD-mediated TGF- $\beta$ signalling maintained SMAD3 for pDC differentiation. Thus, SMAD3 is the pivotal determinant to bifurcate cDC and pDC differentiation in the steady-state condition.

(145 words)

Keywords: cDC; pDC; SMAD3; STAT3; c-SKI 
YOON et al

\section{INTRODUCTION}

A web of cytokine signalling pathways and transcription programs control development of DC subsets from distinct hematopoietic lineages (Lin) (Belz et al, 2012; Dress RJ et al, 2018; Merad et al, 2013; Miller et al, 2012; Murphy et al, 2016). Several cytokine receptors such as Fms-related tyrosine kinase 3 (FLT3; CD135), c-KIT (CD117) and macrophage colonystimulating factor receptor (M-CSFR; CD115) are the markers to distinguish Lin DC progenitors in mouse bone marrow (BM). Common myeloid progenitors (CMPs), common lymphoid progenitor (CLP) and lymphoid-primed multipotent progenitor (LMPP) are the early DC progenitors, which differentiate into the intermediate progenitor, macrophage DC progenitor (MDP). Downstream of MDP is the common DC progenitors (CDPs) comprised of $\mathrm{CD} 115^{+}$and $\mathrm{CD} 115^{-} \mathrm{CDPs}$, which give rise to conventional/classical DC (cDCs) and plasmacytoid DCs (pDCs), respectively, in the steady state condition (Onai et al, 2007; Onai et al, 2016; Schraml et al, 2015). CDPs give rise to $\operatorname{Lin}^{-} \mathrm{CD} 11 \mathrm{c}^{+} \mathrm{MHCII} \mathrm{CD}^{-} 135^{+} \mathrm{CD} 172 \alpha^{-}$preDCs divided into four subsets based on the expression of sialic acid binding Ig-like lectin (Siglec)-H and Ly6C, of which SiglecH ${ }^{+}$subsets have a pDC potential, while SiglecH subsets have a cDC potential (Schlitzer et al, 2015). Pre-cDCs have been defined as

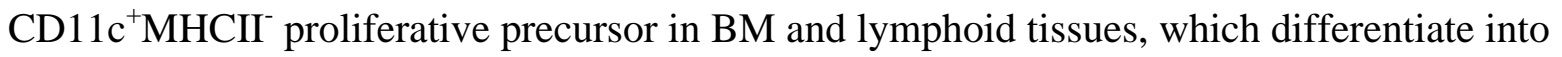
$\mathrm{CD}^{+}$and $\mathrm{CD} 11 \mathrm{~b}^{+} \mathrm{cDCs}$ but not into pDCs (Diao et al, 2006; Naik et al, 2006).

Transcriptome analyses of DC subsets have revealed the essential roles of transcription factors for $\mathrm{cDC}$ and pDC differentiation (Miller et al, 2012; Murphy et al, 2016). The helixloop-helix (HLH) transcription factor, inhibitor of DNA binding protein 2 (ID2) is required for the development of splenic CD8 $\alpha^{+}$DC subset and Langerhans cells (Hacker et al, 2003). Interferon regulatory factors (IRF)-2, IRF-4 and IRF-8 regulate $\mathrm{cDC}$ and $\mathrm{pDC}$ differentiation (Merad et al, 2013). Basic HLH transcription factor (E protein) E2-2/Tcf4 is a specific transcriptional regulator of pDC, which directly activates pDC-related genes such as Irf8 and 


\section{YOON et al}

Spib (Cisse et al, 2008). ID2 and E2-2 induce cDC and pDC, respectively with mutual antagonism (Ghosh et al, 2010). The ETS transcription factor, Spi-B expressed in pDC precursors is required for pDC development (Schotte et al, 2003, Schotte et al, 2004). E2-2 and Spi-B mutually enhance their expressions and cooperate to induce the development of human pDC (Nagasawa et al, 2008). IKAROS, a zinc finger protein is required for $\mathrm{pDC}$ differentiation by repressing non-pDC gene expression (Allman et al, 2006). STAT3 is required for FLT3-dependent DC differentiation (Laouar et al, 2003). Although TGF- $\beta$ has been reported to regulate some of these factors for DC development as introduced below, network of TGF- $\beta$ signalling pathways and these transcription factors still remains largely to be determined.

TGF- $\beta$ pleiotropically regulates hematopoiesis and immune cell development (Blank et al, 2015; Challen et al, 2010; Sanjabi et al, 2017; Söderberg et al, 2009). TGF- $\beta$ exerts the differential effects on DC development in ontogenetic stage-dependent manners (Seeger et al, 2015). TGF- $\beta$ promotes DC development from $\mathrm{CD} 34^{+}$hemopoietic progenitors (Riedl et al, 1997; Strobl et al, 1996). TGF- $\beta 1$ is required for immature DC development, whereas it blocks DC maturation (Yamaguchi et al, 1997). TGF- $\beta 1$ directs differentiation of CDP into cDCs by inducing cDC instructive factors, IRF4 and RelB, and pDC inhibitory factor, ID2 (Felker et al, 2010). TGF- $\beta 1$ induces DC-associated genes such as Flt3, Irf4 and Irf8 in multipotent progenitors at steady state (Sere et al, 2012). Canonical TGF- $\beta$ signalling pathway is initiated by ligand-bound activated TGF- $\beta$ type I receptor (T $\beta$ RI)-phosphorylated TGF- $\beta$ receptor-regulated SMADs (R-SMADs): SMAD2 and SMAD3. Despite their high homology, SMAD2 and SMAD3 exert the distinct functions depending on the context (Brown et al, 2007; Heldin et al, 2012; Massague et al, 2005). Signalling mechanisms underlying pleiotropic functions of TGF- $\beta$ in differentiation of DC subsets from their specific precursors remain unknown. 
YOON et al

Here, we have found that SMAD3 is specifically repressed in CD $115^{+} \mathrm{CDP}$, pre-cDCs and cDCs, despite its ubiquitous and constant expression in normal cells in the steady state condition. SMAD3 represses the transcription factors crucial for $\mathrm{cDC}$ differentiation such as FLT3, IRF4 and ID2. We have discovered that STAT3 represses SMAD3 for cDC differentiation in cooperation with c-SKI, one of the SKI/SNO protooncoproteins that inhibit TGF- $\beta$ signalling as the transcriptional corepressor of the SMAD proteins (Deheuninck et al, 2009; Massague et al, 2005). By contrast, SMAD3 self-induced by SMAD2/3/4 upregulates the pDC-related genes such as Spi-B, E2-2 and IKAROS for pDC differentiation from prepDCs, which are substantially deficient in Smad3 null mice. These findings indicate that downregulation or maintenance of SMAD3 expression determines the fate of DC precursors into cDCs and pDCs. 
YOON et al

\section{RESULTS}

\section{Selective downregulation of SMAD3 in cDCs}

We examined the basal expression patterns of SMAD2 and SMAD3 in LMPP as Lin ${ }^{-S c a-}$ $1^{+} \mathrm{CD} 34^{+} \mathrm{CD} 117^{+} \mathrm{CD} 135^{+}$cells, DC progenitor cells: MDP as Lin $^{-}$ $\mathrm{CD} 117^{\text {hi }} \mathrm{CD} 135^{+} \mathrm{CD} 115^{+} \mathrm{Sca}-1^{-}$cells, $\mathrm{CD} 115^{+} \mathrm{CDP}$ as $\mathrm{Lin}^{-} \mathrm{CD} 117^{\mathrm{int}} \mathrm{CD} 135^{+} \mathrm{CD} 115^{+} \mathrm{CD} 127^{-}$ cells, CD115 $\mathrm{CDP}$ as $\operatorname{Lin}^{-} \mathrm{CD} 117^{\mathrm{int}} \mathrm{CD} 135^{+} \mathrm{CD} 115^{-} \mathrm{CD} 127^{-}$cells (Fogg et al, 2006; Onai et al, 2016), SiglecH'Ly6C $/$ SiglecH Ly6C $^{+} /$SiglecH $^{+} \mathrm{CD}^{-} 1 \mathrm{c}^{+} \mathrm{MHCII}^{-} \mathrm{CD} 135^{+} \mathrm{CD} 172 \alpha^{-}$pre-DCs (Schlitzer et al, 2015) and differentiated DCs: BM CD11 $\mathrm{c}^{\mathrm{hi}} \mathrm{cDCs}, \mathrm{BM}$ PDCA-1 ${ }^{+}$pDCs, splenic CD $11 \mathrm{c}^{\text {hi }} \mathrm{cDCs}$, splenic PDCA- $1^{+}$pDCs, lamina propria and Peyer's patch cDCs of C57BL/6 mice. We also examined GM-CSF plus IL-4-induced BM-derived DCs (BMDCs) that yield CD11 $b^{+} \mathrm{cDCs}$ and FLT3L-induced BMDCs that yield both $\mathrm{cDCs}$ and $\mathrm{pDCs}$ (Waskow et al, 2008; Yamaguchi et al, 1997). SMAD2 mRNA was expressed in all examined cells, whereas SMAD3 mRNA expressed in MDP, CD115 CDP, SiglecH ${ }^{+}$prepDCs and pDCs was reduced to almost undetectable level in $\mathrm{CD}_{11} 5^{+} \mathrm{CDP}$, SiglecH ${ }^{-}$precDCs and cDCs (Figure 1A and S1A). Immunoblotting confirmed that SMAD2 protein (60 $\mathrm{kDa})$ kept expressed, whereas SMAD3 protein $(50 \mathrm{kDa})$ expressed in whole $\mathrm{BM}$ was reduced to undetectable level in GM-CSF plus IL-4-induced BMDCs (Figure S1B). Immunocytochemistry using proximity ligation assay (PLA) showed that SMAD3 protein expressed in LMPP, MDP, CD115- CDP, SiglecH ${ }^{+}$pre-pDCs and pDCs was not detected in $\mathrm{CD}_{115^{+} \mathrm{CDP}, \text { SiglecH }}^{-}$pre-cDCs and cDCs, whereas SMAD2 protein was expressed in all subsets (Figure 1B and S1C). SMADs are usually ubiquitously expressed in normal cells (Brown et al, 2007) as we observed their expression in naïve and activated CD $4^{+} \mathrm{T}$ cells and macrophages (Figure S1D). Thus, SMAD3 is selectively and specifically downregulated in cDCs from their upstream developmental stage at CD115 ${ }^{+} \mathrm{CDP}$. 
YOON et al

\section{SMAD3-mediated TGF- $\beta$ signalling induces $\mathrm{pDC}$ while inhibits $\mathrm{CDC}$ differentiation}

Mutually exclusive expression patterns of SMAD3 in cDCs and pDCs led us to examine the effects of forced expression or knockdown of SMAD3 on DC differentiation using FLT3Linduced or GM-CSF plus IL-4-induced BMDCs transfected with either SMAD3 DNA or SMAD3 siRNA four hours prior to culture. Overexpression of SMAD3 resulted in significant increase in MDP and CD115 CDP while substantial loss of CD115 ${ }^{+} \mathrm{CDP}$ in FLT3L-induced BMDCs (Figure 2A, upper panels). By contrast, knockdown of SMAD3 significantly decreased MDP, while increased CD115 CDP in both FLT3L-induced or GM-CSF plus IL4-induced BMDCs (Figure 2A and S2A, lower panels). Forced expression of SMAD3 resulted in significant decrease in $\mathrm{MHCII}^{+} \mathrm{CD} 11 \mathrm{c}^{+}, \mathrm{CD} 11 \mathrm{~b}^{+} \mathrm{CD} 11 \mathrm{c}^{+} \mathrm{cDCs}$ and $\mathrm{CD} 24^{+} \mathrm{CD} 11 \mathrm{c}^{+}$ cDCs with significant increase in PDCA $-1^{+} \mathrm{B} 220^{+} \mathrm{pDCs}$ in FLT3L-induced BMDCs, whereas knockdown of SMAD3 resulted in significant increase in $\mathrm{MHCII}^{+} \mathrm{CD} 11 \mathrm{c}^{+}, \mathrm{CD} 11 \mathrm{~b}^{+} \mathrm{CD} 11 \mathrm{c}^{+}$ cDCs and CD $24^{+} \mathrm{CD} 11 \mathrm{c}^{+} \mathrm{cDCs}$ with significant decrease in PDCA- $1^{+} \mathrm{B} 220^{+} \mathrm{pDCs}$ in both FLT3L-induced and GM-CSF plus IL-4-induced BMDCs (Figure 2B and S2B). Forced expression of SMAD3 slightly induced pDCs even in GM-CSF plus IL-4-induced BMDCs, which do not develop pDC (Figure S2A and S2B). Forced expression of SMAD3 showed the plasmacytoid morphology with no dendrite formation, whereas knockdown of SMAD3 developed more dendrites compared with control pcDNA or siRNA in BMDCs (Figure 2C and S2C). Knockdown or forced expression of SMAD3 was confirmed by RT-PCR (Figure S2D). SMAD2 and SMAD3 are the R-SMADs shared by TGF- $\beta$ and Activin among TGF- $\beta$ superfamily cytokines (Massague et al, 2005). Activin A (10 ng/ml) showed no effect on FLT3L or GM-CSF plus IL-4-induced BMDC differentiation (Figure 2D and S2E). High concentration of TGF- $\beta 1$ ( $5 \mathrm{ng} / \mathrm{ml})$ completely blocked FLT3L or GM-CSF plus IL-4induced Smad3 $3^{+/+}$BMDC differentiation, which was abolished in Smad3 ${ }^{-/}$BMDCs (Figure $2 \mathrm{D}$ and S2E), indicating that potent inhibitory effect of high-dose TGF- $\beta$ on DC 
YOON et al

differentiation is SMAD3-dependent. These data show that SMAD3-mediated TGF- $\beta$ signalling induces pDC differentiation while inhibits $\mathrm{cDC}$ differentiation.

\section{Decreased pDCs and increased cDCs in $\mathrm{Smad3}^{-/-}$mice}

We next examined the in vivo effect of SMAD3 deficiency on DC differentiation using $\mathrm{Smad}^{-/-}$mice. We confirmed that the proportions of the hematopoietic progenitor cells detected as c-kit ${ }^{+} \operatorname{Lin}^{-} \mathrm{Sca}-1^{+}(\mathrm{KLS})$ or CD $34^{+} \mathrm{KLS}$ cells, LMPP, CMP as Lin ${ }^{-S c a-1}{ }^{-} \mathrm{CD} 16 / 32^{-}$ $\mathrm{CD}_{3} 4^{+} \mathrm{CD} 117^{+}$and granulocyte macrophage progenitor (GMP) as Lin'Sca- ${ }^{-}$

$\mathrm{CD} 16 / 32^{+} \mathrm{CD} 34^{+} \mathrm{CD} 117^{+}$were unaltered in BM of 8-weeks old Smad3 ${ }^{--}$mice compared with $\mathrm{BM}$ of $\mathrm{Smad}^{+/+}$mice bred in specific-pathogen free environment before the onset of any signs of inflammation (Yang et al, 1999; Yoon et al, 2015) (Figure S3). We observed the significantly increased $\mathrm{CD} 115^{+} \mathrm{CDP}$ with decreased MDP and unaltered CD115 CDP in BM of $S m a d 3^{-/}$mice compared with BM of $S m a d 3^{+/+}$mice (Figure 3A). DNGR-1 (encoded by the $C l e c 9 a$ gene and also known as CLEC9A and CD370) positive CDPs are cDC-restricted (Schraml et al, 2013). CX3CR1 is expressed on MDP and cDC-P (Liu et al, 2009). Cx3cr1 and Dngrl mRNA expression in Lin ${ }^{-C D} 115^{+} \mathrm{BM}$ cells and CX3CR $1^{+} \mathrm{CD} 370^{+} \mathrm{Lin}^{-}$ $\mathrm{CD} 117^{\mathrm{int}} \mathrm{CD} 135^{+} \mathrm{CD} 115^{+} \mathrm{BM}$ cells were significantly increased in Smad3 $3^{--}$mice compared with $\mathrm{Smad}^{+/+}$mice (Figure 3B). SiglecH ${ }^{+}$pre-DCs containing a pDC potential were profoundly reduced, while SiglecH ${ }^{-} \mathrm{Ly}_{6 \mathrm{C}^{+}}$and SiglecH $\mathrm{Ly}^{-} \mathrm{C}^{-}$pre-DCs with a cDC potential were significantly increased in BM of $\operatorname{Smad}^{-/-}$mice compared with BM of $\operatorname{Smad}^{+/+}$mice (Figure 3C). Total cDCs in BM, spleen, superficial and mesenteric lymph nodes of Smad3 $3^{-/-}$ mice were significantly increased compared with those of $\mathrm{Smad}^{+/+}$mice, whereas Siglec $\mathrm{H}^{+} \mathrm{PDCA} 1^{+} \mathrm{B} 220^{+}$pDCs were substantially undetected in those of $\mathrm{Smad}^{-{ }^{--}}$mice (Figure 3D). Immunophenotyping of DC subsets in Smad3 deficient mice shows that 
YOON et al

SMAD3 deficiency facilitates cDC differentiation at the developmental stage between MDP and $\mathrm{CD} 115^{+} \mathrm{CDP}$, while it blocks differentiation of pre-pDCs and pDCs in the steady state.

\section{SMAD3 represses cDC-related genes while induces pDC-related genes}

To identify the responsible genes to facilitate $\mathrm{cDC}$ while to inhibit $\mathrm{pDC}$ differentiation in $\mathrm{Smad}^{-/}$mice, we compared the mRNA expressions of the cytokines, their signalling molecules and the transcription factors essential for DC differentiation in DC precursors and subsets of $\mathrm{Smad}^{-/-}$mice with those of littermate control $\mathrm{Smad}^{+/+}$mice. It was impossible to sort out pre-pDCs and pDCs from BM and lymphoid organs of Smad3 $3^{--}$mice because they were substantially deficient (Figure 3C and 3D). Smad3 $3^{-/}$CD $115^{+}$CDPs, pre-cDCs and cDCs expressed significantly higher levels of cDC-related genes: Flt3, Irf4 and Id2 compared with $\mathrm{Smad}^{+/+}$controls, whereas $\mathrm{Smad}^{-/-}$and $\mathrm{Smad}^{+/+}$CD115 CDPs expressed similar levels of pDC markers: Siglech (Takagi et al, 2011), Bst2 encoding PDCA-1 (Blasius et al, 2006) and the transcription factors essential for pDC differentiation: Spib, E2-2 and Ikaros (Figure 4A). To identify the target genes for SMAD3 to induce $\mathrm{pDC}$ while to inhibit cDC differentiation, we screened these genes in BMDCs transfected with either SMAD3 DNA or control pcDNA. We found that forced expression of SMAD3 significantly upregulated the mRNA expression of pDC-related genes: Spib, E2-2 and Ikaros in FLT3L-induced BMDCs (Figure 4B and S4A). SMAD3 slightly upregulated these pDC-related genes even in GM-CSF plus IL-4induced BMDCs (Figure S4A and S4B). Low concentrations of TGF- $\beta 1(0.1,0.2 \mathrm{ng} / \mathrm{ml})$ showed the same effect with forced expression of SMAD3 on these pDC-related genes in both FLT3L-induced and GM-CSF plus IL-4-induced Smad $3^{+/+}$BMDCs, which was abolished in Smad3 ${ }^{-/}$BMDCs (Figure 4C and S4C). By contrast, forced expression of SMAD3 significantly repressed the mRNA expression of cDC-related genes: Flt3, Irf4 and Id2 in FLT3L-induced BMDCs, Flt3 and Irf4 in GM-CSF plus IL-4-induced BMDCs (Figure 
YOON et al

4D, S4A and S4D). Low concentrations of TGF- $\beta 1$ repressed these cDC-related genes in Smad3 $^{+/+}$BMDCs, which remained in Smad3 ${ }^{-/}$BMDCs (Figure 4E and S4E). High concentrations of TGF- $\beta 1$ completely repressed both $\mathrm{cDC}$ and $\mathrm{pDC}$-related genes in Smad $^{+/+}$BMDCs (Figure 4C and 4E). Thus, SMAD3-mediated low-dose TGF- $\beta$ signalling induces pDC-related genes while represses cDC-related genes.

\section{TGF- $\beta$ induces transactivation of the Smad3 gene, thereby pDC differentiation}

Because low concentration of TGF- $\beta$ upregulated pDC-related genes while repressed cDCrelated genes, we examined the dose effect of TGF- $\beta$ on DC differentiation. In accordance with the effect on the gene expression, low concentrations of TGF- $\beta 1$ significantly increased pDC differentiation while suppressed cDC differentiation in FLT3L-induced BMDCs, which was abolished in $\mathrm{Smad3}^{--}$BMDCs (Figure 5A). Low concentrations of TGF- $\beta 1$ induced pDC differentiation even in GM-CSF plus IL-4-induced Smad $3^{+/+}$BMDCs, which was abolished in $\mathrm{Smad3}^{-/}$BMDCs (Figure 5B). High concentrations of TGF- $\beta 1$ potently inhibited both pDC and $\mathrm{CDC}$ differentiation (Figure 5A and 5B). SMAD3 was C-terminally phosphorylated in the nuclei in CD115 CDP, pre-pDCs and pDCs (Figure 1B and S1C). PLA showed that low concentrations of TGF- $\beta 1$ upregulated the expression and C-terminal phosphorylation levels of SMAD3 proteins (Figure 5C). These data verify that SMAD3-mediated low-dose TGF- $\beta$ signalling induces $\mathrm{pDC}$ while represses $\mathrm{cDC}$ differentiation.

To investigate the mechanisms how TGF- $\beta$ signalling maintains the Smad3 mRNA expression for $\mathrm{pDC}$ differentiation, we examined the effect of SMAD-mediated TGF- $\beta$ signalling on the Smad3 gene promoter activity using the luciferase reporter spanning 2 kilobase upstream of the first exons of the Smad3 genes transfected in FLT3L-induced BMDCs. TGF- $\beta 1$ induced the Smad3 promoter activity in a dose-dependent manner (Figure 5D). Discrepancy between lower SMAD3 protein expression and the dose dependency 
YOON et al

observed in luciferase assay in FLT3L-induced BMDCs treated with the high concentrations of TGF- $\beta 1(0.5,1.0,5.0 \mathrm{ng} / \mathrm{ml})$ might be due to the potent inhibition of total DC differentiation (Figure 2D and S2E) and the ligand-dependent degradation of SMAD3 (Fukuchi et al, 2001). SMAD2, SMAD3, SMAD4 and their transcription coactivator and histone acetyl-transferase p300 (Massague et al, 2005; Heldin et al, 2012) synergistically induced the $\operatorname{Smad} 3$ promoter activity as well as TGF- $\beta 1$ (Figure 5E). Chromatin immunoprecipitation (ChIP) showed that SMAD2, SMAD3, SMAD4 and p300 were bound to the same sites in PDCA $1^{+}$cells isolated from FLT3L-induced BMDCs (-1700 to -1534 and -524 to -372 ), which were epigenetically active with acetyl histone H3K23 and trimethyl histone H3K27 (Figure 5F). Taken together, transactivation of SMAD3 via canonical TGF- $\beta$ signalling pathway initiated by low-dose TGF- $\beta$ induces the essential transcription factors for pDC differentiation.

\section{STAT3 and c-SKI repress transcription of SMAD3 for cDC differentiation}

We next investigated the mechanisms how SMAD3 is downregulated in CD115 ${ }^{+} \mathrm{CDP}$ for cDC differentiation. The ligand of CD115, M-CSF induces STAT3 activation in macrophages (Novak et al, 1995). STAT3 functions as the signalling molecule of FLT3L and GM-CSF (Li et al, 2013; Onai et al, 2006; Wan et al, 2013) and is essential for FLT3Lresponsive DC progenitor proliferation (Laouar et al, 2003). Thus, we examined the effect of STAT3 on SMAD3 expression in BMDCs transfected with STAT3 and control pcDNA or siSTAT3 and control siRNA. Forced expression of STAT3 suppressed, whereas knockdown of STAT3 upregulated the expression of Smad3 mRNA (Figure 6A and S5A). We examined whether and how STAT3 regulates the Smad3 gene promoter activity using the Smad3 gene promoter luciferase reporter construct transfected in FLT3L-induced or GM-CSF plus IL-4induced BMDCs. CD11 b ${ }^{+}$cells were sorted as cDCs before cell lysis for FLT3L-induced 
YOON et al

BMDCs. SMAD2 and SMAD3 synergistically induced the Smad3 promoter activity, which was repressed by STAT3 (Figure 6B and S5B). We screened the representative transcriptional repressors of R-SMADs: SKI/SnoN and TGIF as a corepressor of STAT3 (Deheuninck et al, 2009; Heldin et al, 2012; Massague et al, 2005). Among them, c-SKI showed the synergy with STAT3 to repress the Smad3 promoter activity (Figure S5C). Knockdown or forced expression of c-SKI and STAT3 showed the same effect on Smad3 mRNA expression in FLT3L-induced and GM-CSF plus IL-4-induced BMDCs (Figure 6A and S5A). Knockdown of c-SKI by siRNA completely abolished the repressive effect of STAT3 on the SMAD2/3-induced Smad3 promoter activation (Figure 6C and S5D). By contrast, c-SKI alone retained the repressive effect on the SMAD2/3-induced Smad3 promoter activation when STAT3 was knocked-down, although the synergistic repressive effect of c-SKI and STAT3 was more effective (Figure 6D). ChIP showed that SMAD2 was bound to the same sites with STAT3 and c-SKI in FLT3L-induced BMDCs (-1196 to -1003 and -220 to -28), which were epigenetically inactive with trimethyl histone H3K27 (Figure 6E). These data indicate that STAT3 in synergy with c-SKI represses SMAD-induced transcription of the Smad3 gene for cDC differentiation.

\section{Interaction of phosphorylated STAT3 with c-SKI is essential for repression of SMAD3 in $\mathbf{c D C}$}

We sought to confirm the physiological interactions between STAT3, c-SKI and SMAD2 in DC progenitors, pre-DCs, DC subsets, FLT3L-induced and GM-CSF plus IL-4-induced BMDCs. PLA showed the interaction of c-SKI with STAT3 and SMAD2 in CD115 ${ }^{+}$CDP, pre-cDCs, cDCs and CD11c $\mathrm{c}^{\text {hi }}$ BMDCs, but not in the early progenitors, pre-pDCs and pDCs (Figure 7A and S6A). Knockdown of c-SKI by siRNA abolished the interaction of SMAD2 
YOON et al

and STAT3, whereas knockdown of STAT3 had no effect on the interaction of c-SKI and SMAD2 in CD11 $\mathrm{c}^{\text {hi }}$ BMDCs (Figure 7B).

We next investigated the mechanisms how c-SKI and STAT3 repress transcription of the Smad3 gene using the Smad3 gene promoter luciferase reporter construct with various combinations of mutants of c-SKI and STAT3 transfected in CD11 b ${ }^{+}$FLT3L-induced or GMCSF plus IL-4-induced BMDCs. SKI interacts with SMAD2 and SMAD3 through its Nterminal region or with SMAD4 through its SAND-like domain to block the ability of the SMAD complexes to activate transcription of TGF- $\beta$ target genes (Akiyoshi et al, 1999; Massague et al, 2005; Suzuki et al, 2004; Takeda et al, 2004). A mutant of c-SKI that does not interact with SMAD2/3 $(\Delta 2 / 3)$ failed to repress the $S m a d 3$ promoter activity, whereas a mutant of c-SKI that does not interact with SMAD4 (W274E) (Wu et al, 2002) retained the repressive effect on the $S m a d 3$ promoter activity (Figure $7 \mathrm{C}$ and S6B). Transfection of $\Delta 2 / 3$ and c-SKI siRNA failed to induce cDC differentiation, whereas W274E significantly upregulated cDC differentiation as well as wild type c-SKI (Figure 7D and S6C). These data verify that interaction of c-SKI with SMAD2 and SMAD3 is required for STAT3-mediated repression of SMAD3 and cDC differentiation. STAT3 is phosphorylated at Y705 and S727 residues upon stimulation (Hillmer et al, 2016). Inactive mutants of STAT3 at Y705 and S727 residues, Y705F and S727A, respectively, abolished the repressive effect on SMAD2/3induced Smad3 promoter activition in CD11 ${ }^{+}$FLT3L-induced or GM-CSF plus IL-4-induced BMDCs (Figure 7E and S6D). Forced expression of STAT3 signifiantly upregulated cDC differentiation to the same degree as forced expression of c-SKI, which was abolised by Y705F and S727A mutations to the same degree as STAT3 siRNA (Figure 7F and S6E). Thus, c-SKI is necessary for phosphorylated STAT3 at Y705 and S727 to interact with TGF$\beta$ R-SMADs to repress transcription of the Smad3 gene for cDC differentiation. 
YOON et al

\section{DISCUSSION}

Major DC subsets are classified into cDCs and pDCs, even though recent studies have shown increasingly complex classification of DC subpopulations and progenitors during ontogeny (Dress et al, 2018). Signalling mechanisms how TGF- $\beta$ regulates the differentiation of DC subsets in the steady state remained largely unknown, although its importance in immunogenic and tolerogenic functions of the differentiated DCs have been appreciated (Seeger et al, 2015). In this study, specific repression of SMAD3 in cDCs and their progenitors: pre-cDCs and $\mathrm{CD} 115^{+} \mathrm{CDP}$ led us to uncover its pivotal role to bifurcate $\mathrm{DC}$ differentiation into cDCs and pDCs.

SMAD2 and SMAD3 are ubiquitously and constitutively expressed in normal cells in general, whereas their loss is frequently observed in various cancers (Brown et al., 2007; Heldin et al., 2012). They have high amino acid sequence identity in their MH2 domains containing two C-terminal serine residues, 465/467; nevertheless they regulate the same or distinct sets of TGF- $\beta$ target genes to exert redundant or distinct functions depending on the context (Brown et al, 2007, Massague et al, 2005). However, the precise mechanisms how they are selected for distinct functions by the context still remain largely unknown. In order to prevent continuous SMAD-mediated TGF- $\beta$ signalling in normal epithelial cells, SMAD2 and SMAD3 are negatively regulated by diverse mechanisms (Brown et al, 2007). TGF- $\beta$ has been shown to downregulate SMAD3 in lung epithelial cells through decreased transcription (Yanagisawa et al, 1998) or in epitheilial-to mesenchymal transition of human glomerular mesangial cells through decreased transcription and increased ubiquitination (Poncelet et al, 2007), suggesting that downregulation of SMAD3 can be one of the mechanisms to select the appropriate R-SMAD in response to TGF- $\beta$ by the context. This study is the first to show that the transcriptional downregulation of SMAD3 is indispensable for differentiation of the normal immune cell subsets in the steady-state. Further studies are required to explore the 


\section{YOON et al}

distinct regulation of R-SMADs in immune cells including the effector DC subsets in the pathophysiological setting (Merad et al, 2013).

This study shows that STAT3 transcriptionally represses SMAD3 to derepress cDC-related genes: IRF4, ID2 and FLT3 in cDCs, pre-cDC and CD115 ${ }^{+} \mathrm{CDP}$. Indispensable role of STAT3 in DC development has been shown by loss of cDCs by deletion of STAT3 in vivo (Laouar et al, 2003) and promotion of DC maturation from the progenitors by overexpression of STAT3 (Onai et al, 2006). Engagement of FLT3L and FLT3 expressed on DC precursors such as MDP, CDPs, and pre-cDCs (Liu et al, 2009; Onai et al, 2007) induces rapid phosphorylation of STAT3 and FLT3L-responsive DC progenitor proliferation (Li et al, 2013). STAT3 transiently activated by GM-CSF promotes differentiation of myeloid lineages including cDCs (Merad et al, 2013; Wan et al, 2013). Colony stimulating factor, the ligand of CD115 induces STAT3 activation (Novak et al, 1995). This study has revealed the previously unknown mechanism how STAT3 induces cDC differentiation through repressing SMAD3, a repressor of the representative cDC-related genes.

We have further elucidated that c-SKI is required for STAT3 to repress SMAD3 for cDC differentiation. SKI and the closely related SnoN oncogenes act as transcriptional corepressors in TGF- $\beta$ signalling through interaction with SMADs (Akiyoshi et al, 1999; Suzuki et al, 2004; Wu et al, 2002). Although SKI is more widely expressed than SnoN in mature hematopoietic cells and play crucial roles in hematopoiesis and myeloproliferative diseases (Pearson-White et al, 1995; Singbrant et al, 2014), very little was known about its roles in differentiation and functions of immune cells. We have previously shown that SKI and SnoN oncoproteins cooperate with phosphorylated STAT3 in an adenocarcinoma lung cancer cell line, HCC827 to repress transcription of the Smad3 gene, which renders the sensitive cells resistant to gefitinib (Makino et al, 2017). Here, we have found that c-SKI, but not SnoN is indispensable for STAT3 to repress the Smad3 gene for cDC differentiation 


\section{YOON et al}

rather than playing a conventional role as a transcriptional co-repressor of SMADs. In hematopoietic cells, SKI represses retinoic acid receptor signalling (Dahl et al, 1998), which enhances SMAD3/SMAD4-driven transactivation (Pendaries et al, 2003). SKI induces a gene signature associated with hematopoietic stem cells (HSCs) and myeloid differentiation, as well as hepatocyte growth factor (HGF) signalling (Singbrant et al, 2014). These previous reports and our finding suggest the possibility that HGF signals via STAT3 (Schaper et al, 1997) might induce synergy with c-SKI to repress SMAD3 toward myeloid differentiation. Distinct binding sites of SMADs, p300, STAT3 and c-SKI in the Smad3 promoter in pDCs and cDCs shown in this study and HCC827 lung cancer cell line are consistent with the previous report showing that cell-type-specific master transcription factors direct SMAD3 to distinct specific binding sites to determine cell-type-specific responses to TGF- $\beta$ signaling (Mullen et al, 2011).

Studies prior to the identification of distinct CDP subsets (Onai et al, 2013) have shown that TGF- $\beta$ facilitates $c D C$ differentiation from CDP by inducing the essential factors for $\mathrm{cDC}$ differentiation such as IRF4, IRF8, RelB, ID2 and FLT3 (Felker et al, 2010; Sere et al, 2012). They have reported that TGF- $\beta$ induces ID2 (Hacker et al, 2003). By contrast, TGF- $\beta$ represses ID2 in epithelial cells (Zavadil et al, 2005), which is consistent with our data. The discrepancy between these previous reports and this study may be attributed to their two-step amplification and differentiation culture systems. The first-step amplification culture contains SCF, hyper-IL-6 and insulin-like growth factor-1, which modulate STAT and SMAD signalling pathways (Rojas et al, 2016; Sarenac et al, 2016; Yoon et al, 2015). They report that the amplified DC precursor cells with these cytokines prior to DC differentiation are CDP (Felker et al, 2010), which may be regulated by TGF- $\beta$ through a mechanism distinct from the upstream progenitor cells. The second-step differentiation culture contains GM-CSF and IL-4. However, neither TGF- $\beta$ nor forced expression and knockdown of SMAD3 


\section{YOON et al}

affected the expression of ID2 in GM-CSF plus IL-4-induced BMDCs in our system.

Moreover, the expression of ID2 is not downregulated as deduced from these reports, but rather significantly upregulated in cDCs, pre-cDCs and CD $115^{+} \mathrm{CDP}$ in $\mathrm{Smad}^{{ }^{-/}}$mice. These data support the pre-selection of committed CDP subset(s) in the first-step culture containing FLT3L in these previous reports.

In contrast with the repressive effect on cDC-related genes, SMAD3 induces pDC-related genes. Consistently, we have found that SMAD3 deficiency in vivo resulted in substantial loss of pDCs and pre-pDCs, indicating the indispensable role of SMAD3 for pDC differentiation at the developmental stage of pre-pDCs. We have found that low-dose TGF- $\beta$ in vitro that represents in vivo steady-state physiological function ( $\mathrm{Zi}$ et al, 2012) transactivates SMAD3 in BMDCs, which then induces pDC-related genes: Spib, Tcf4 and Ikaros (Allman et al, 2006; Cisse et al, 2008; Ghosh et al, 2010; Nagasawa et al, 2008, Reizis et al, 2019). Significantly more profound decrease of pDCs in SMAD3 deficient mice compared with the mice deficient in E2-2 (Ghosh et al, 2010; Grajkowska et al, 2017) also supports our finding that SMAD3 is the upstream inducer of these pDC-related genes. The proximal promoter regions of these pDC-related genes and pDC marker genes: Siglech, Bst2 upregulated by SMAD3-mediated TGF- $\beta$ signalling are relatively abundant in the SMAD3/SMAD4 binding sequence termed CAGA box (Dennler et al, 1998). In the light of ubiquitous expression of SMAD3 in the steady-state condition, future studies are required to identify the factors networking with SMAD3 to specifically induce pDC differentiation. TGF- $\beta$ exerts the bidirectional effects on proliferation and differentiation vs. quiescence depending on the HSC subtypes (Blank et al, 2015). Extracellular matrix stores and activates latent TGF- $\beta$ in BM to activate SMAD-mediated TGF- $\beta$ signalling in HSCs and various hematopoietic progenitor cell populations (Massague, et al, 2012; Robertson, et al, 2016; Soderberg et al, 2009). TGF- $\beta$ induces HSC hibernation (Yamazaki et al, 2009). TGF- $\beta$ - 


\section{YOON et al}

SMAD3 signalling has been implicated to connect FOXO-p57Kip2 signalling to induce HSC quiescence and self-renewal (Naka et al, 2017). Considering the crucial role of SMAD3 in maintaining stem cell quiescence reported in these previous studies, nuclear localization of RSMADs in freshly isolated BM progenitor cells suggests that the early DC progenitors upstream of MDPs are maintained by SMAD-mediated canonical TGF- $\beta$ pathway. In summary, we demonstrate the previously unknown fate determinant roles of SMAD3 as a negative regulator of $\mathrm{cDC}$ differentiation and a positive regulator of $\mathrm{pDC}$ differentiation in the steady-state. Repression of SMAD3 by phosphorylated STAT3 and c-SKI is required for commitment to $\mathrm{cDC}$, whereas maintenance of SMAD3 via canonical TGF- $\beta$ signalling is required for $\mathrm{pDC}$ differentiation. Although we have narrowed down $\mathrm{CD} 115^{+} \mathrm{CDP}$ and pre$\mathrm{pDC}$ in which SMAD3 expression is regulated for differentiation of $\mathrm{cDC}$ and $\mathrm{pDC}$, respectively, our findings would have potential for future studies to identify the unknown lineage-specific DC progenitor cells targeted by SMAD3. 
YOON et al

\section{ACKNOWLEDGEMENTS}

We thank Dr. Michael Sporn (Dartmouth Medical College, USA) and Dr. Lalage Wakefield (National Institutes of Health, USA) for helpful discussions and critical reading of the manuscript. We thank Dr. Chuxia Deng (National Institutes of Health, USA) for Smad3 $3^{\text {ex8/ex } 8}$ mice. The project was funded by NRF-2015R1A1A3A04001051, NRF-2018R1A2B6009255 and JSPS KAKENHI JP16K09908 to M.M., JSPS KAKENHI JP17K15735 and NRF2016R1D1A1B03931785 to JH.Y., JSPS KAKENHI JP18K15252, WISET-2017-083, WISET-2018-737 and NRF-2018R1A6A3A01011885 to E.B., NRF SRC 2017R1A5A1014560 to SH.P. and KHIDI-HI16C1501 to IK.L.

\section{AUTHOR CONTRIBUTIONS}

JH.Y. and M.M. conceived the project idea, designed and performed experiments, analyzed data, and wrote the manuscript. E.B., K.S., M.T., IK.L., JS.H., S.N., T.Y., and T.S. contributed to the animal experiments and drafting the manuscript. Ma.K. and Mi.K. evaluated cytochemical analysis and contributed to drafting the manuscript. JH.J. contributed to the experiments and analyses using flowcytometry and confocal microscopy. SH.P., K.M. and E.B. contributed to the experiments using various mutant constructs and promoter analyses.

\section{COMPETING FINANCIAL INTERESTS}

The authors declare no competing financial interests. 
YOON et al

\section{REREFENCES}

Akiyoshi S, Inoue H, Hanai J, Kusanagi K, Nemoto N, Miyazono K, Kawabata M (1999) cSki acts as a transcriptional co-repressor in transforming growth factor-beta signaling through interaction with smads. J Biol Chem 274: 35269-77

Allman D, Dalod M, Asselin-Paturel C, Delale T, Robbins SH, Trinchieri G, Biron CA, Kastner P, Chan S (2006) Ikaros is required for plasmacytoid dendritic cell differentiation. Blood 108: 4025-34

Belz GT, Nutt SL (2012) Transcriptional programming of the dendritic cell network. Nat Rev Immunol 12: 101-13

Blank U, Karlsson S (2015) TGF-beta signaling in the control of hematopoietic stem cells. Blood 125: 3542-50

Blasius AL, Giurisato E, Cella M, Schreiber RD, Shaw A, Colonna M (2006). Bone marrow stromal cell antigen 2 is a specific marker of type I IFN-producing cells in the naive mouse, but a promiscuous cell surface antigen following IFN stimulation. J Immunol 177: 3260-65.

Brown KA, Pietenpol JA, Moses HL (2007) A tale of two proteins: differential roles and regulation of Smad2 and Smad3 in TGF-beta signaling. J Cell Biochem 101: 9-33

Challen GA, Boles NC, Chambers SM, Goodell MA (2010) Distinct hematopoietic stem cell subtypes are differentially regulated by TGF-beta1. Cell Stem Cell 6: 265-78 
YOON et al

Cisse B, Caton ML, Lehner M, Maeda T, Scheu S, Locksley R, Holmberg D, Zweier C, den

Hollander NS, Kant SG, Holter W, Rauch A, Zhuang Y, Reizis B (2008) Transcription factor

E2-2 is an essential and specific regulator of plasmacytoid dendritic cell development. Cell 135: $37-48$

Dahl R, Kieslinger M, Beug H, Hayman MJ (1998) Transformation of hematopoietic cells by the Ski oncoprotein involves repression of retinoic acid receptor signaling. Proc Natl Acad Sci U S A 95: 11187-92

Deheuninck J, Luo K (2009) Ski and SnoN, potent negative regulators of TGF-beta signaling. Cell Res 19: 47-57

Dennler S, Itoh S, Vivien D, ten Dijke P, Huet S, Gauthier JM (1998) Direct binding of Smad3 and Smad4 to critical TGF beta-inducible elements in the promoter of human plasminogen activator inhibitor-type 1 gene. EMBO J 17: 3091-100

Diao J, Winter E, Cantin C, Chen W, Xu L, Kelvin D, Phillips J, Cattral MS (2006) In situ replication of immediate dendritic cell (DC) precursors contributes to conventional DC homeostasis in lymphoid tissue. J Immunol 176: 7196-206

Dress RJ, Wong AYW, Ginhoux F (2018) Homeostatic control of dendritic cell numbers and differentiation. Immunol Cell Biol 96: 463-476 
YOON et al

Felker P, Sere K, Lin Q, Becker C, Hristov M, Hieronymus T, Zenke M (2010) TGF-beta1 accelerates dendritic cell differentiation from common dendritic cell progenitors and directs subset specification toward conventional dendritic cells. J Immunol 185: 5326-35

Fogg DK, Sibon C, Miled C, Jung S, Aucouturier P, Littman DR, Cumano A, Geissmann F (2006) A clonogenic bone marrow progenitor specific for macrophages and dendritic cells. Science 311: 83-7

Fukuchi M, Imamura T, Chiba T, Ebisawa T, Kawabata M, Tanaka K, Miyazono, K (2001) Ligand-dependent degradation of Smad3 by a ubiquitin ligase complex of ROC1 and associated proteins. Molecular biology of the cell, 12(5) 1431-1443

Ghosh HS, Cisse B, Bunin A, Lewis KL, Reizis B (2010) Continuous expression of the transcription factor e2-2 maintains the cell fate of mature plasmacytoid dendritic cells. Immunity 33: 905-16

Grajkowska LT, Ceribelli M, Lau CM, Warren ME, Tiniakou I, Higa SN, Bunin A, Haecker H, Mirny LA, Staudt LM, Reizis B (2017). Isoform-specific expression and feedback regulation of E protein TCF4 control dendritic cell lineage specification. Immunity 46: 65-77.

Hacker C, Kirsch RD, Ju XS, Hieronymus T, Gust TC, Kuhl C, Jorgas T, Kurz SM, RoseJohn S, Yokota Y, Zenke M (2003) Transcriptional profiling identifies Id2 function in dendritic cell development. Nat Immunol 4: 380-6 
YOON et al

Heldin CH, Moustakas A (2012) Role of Smads in TGFbeta signaling. Cell Tissue Res 347:

$21-36$

Hillmer EJ, Zhang H, Li HS, Watowich SS (2016) STAT3 signaling in immunity. Cytokine Growth Factor Rev 31: 1-15

Laouar Y, Welte T, Fu XY, Flavell RA (2003) STAT3 is required for Flt3L-dependent dendritic cell differentiation. Immunity 19: 903-12

Li HS, Watowich SS (2013) Diversification of dendritic cell subsets: Emerging roles for STAT proteins. JAKSTAT 2: e25112

Liu K, Victora GD, Schwickert TA, Guermonprez P, Meredith MM, Yao K, Chu FF, Randolph GJ, Rudensky AY, Nussenzweig M (2009) In vivo analysis of dendritic cell development and homeostasis. Science 324: 392-7

Makino Y, Yoon JH, Bae E, Kato M, Miyazawa K, Ohira T, Ikeda N, Kuroda M, Mamura M (2017) Repression of Smad3 by Stat3 and c-Ski/SnoN induces gefitinib resistance in lung adenocarcinoma. Biochem Biophys Res Commun 484: 269-277

Massague J, Seoane J, Wotton D (2005) Smad transcription factors. Genes Dev 19: 2783-810

Massague J, Xi Q (2012) TGF-beta control of stem cell differentiation genes. FEBS Lett 586: $1953-8$ 
YOON et al

Merad M, Sathe P, Helft J, Miller J, Mortha A (2013) The dendritic cell lineage: ontogeny and function of dendritic cells and their subsets in the steady state and the inflamed setting. Annu Rev Immunol 31: 563-604

Miller JC, Brown BD, Shay T, Gautier EL, Jojic V, Cohain A, Pandey G, Leboeuf M, Elpek KG, Helft J, Hashimoto D, Chow A, Price J, Greter M, Bogunovic M, Bellemare-Pelletier A, Frenette PS, Randolph GJ, Turley SJ, Merad M et al. (2012) Deciphering the transcriptional network of the dendritic cell lineage. Nat Immunol 13: 888-99

Mullen AC, Orlando DA, Newman JJ, Loven J, Kumar RM, Bilodeau S, Reddy J, Guenther MG, DeKoter RP, Young RA (2011) Master transcription factors determine cell-type-specific responses to TGF-beta signaling. Cell 147: 565-76

Murphy TL, Grajales-Reyes GE, Wu X, Tussiwand R, Briseno CG, Iwata A, Kretzer NM, Durai V, Murphy KM (2016) Transcriptional Control of Dendritic Cell Development. Annu Rev Immunol 34: 93-119

Nagasawa M, Schmidlin H, Hazekamp MG, Schotte R, Blom B (2008) Development of human plasmacytoid dendritic cells depends on the combined action of the basic helix-loophelix factor E2-2 and the Ets factor Spi-B. Eur J Immunol 38: 2389-400

Naik SH, Metcalf D, van Nieuwenhuijze A, Wicks I, Wu L, O'Keeffe M, Shortman K (2006) Intrasplenic steady-state dendritic cell precursors that are distinct from monocytes. Nat Immunol 7: 663-71 
YOON et al

Naka K, Hirao A (2017) Regulation of Hematopoiesis and Hematological Disease by TGFbeta Family Signaling Molecules. Cold Spring Harb Perspect Biol 9

Novak U, Harpur AG, Paradiso L, Kanagasundaram V, Jaworowski A, Wilks AF, Hamilton JA (1995) Colony-stimulating factor 1-induced STAT1 and STAT3 activation is accompanied by phosphorylation of Tyk 2 in macrophages and Tyk 2 and JAK 1 in fibroblasts. Blood 86: 2948-56

Onai N, Kurabayashi K, Hosoi-Amaike M, Toyama-Sorimachi N, Matsushima K, Inaba K, Ohteki T (2013) A clonogenic progenitor with prominent plasmacytoid dendritic cell developmental potential. Immunity 38: 943-57

Onai N, Obata-Onai A, Schmid MA, Ohteki T, Jarrossay D, Manz MG (2007) Identification of clonogenic common Flt3+M-CSFR+ plasmacytoid and conventional dendritic cell progenitors in mouse bone marrow. Nat Immunol 8: 1207-16

Onai N, Obata-Onai A, Tussiwand R, Lanzavecchia A, Manz MG (2006) Activation of the Flt3 signal transduction cascade rescues and enhances type I interferon-producing and dendritic cell development. J Exp Med 203: 227-38

Onai N, Ohteki T (2016) Isolation of Dendritic Cell Progenitor and Bone Marrow Progenitor Cells from Mouse. Methods Mol Biol 1423: 53-9

Pearson-White S, Deacon D, Crittenden R, Brady G, Iscove N, Quesenberry PJ (1995) The ski/sno protooncogene family in hematopoietic development. Blood 86: 2146-55 
YOON et al

Pendaries V, Verrecchia F, Michel S, Mauviel A (2003) Retinoic acid receptors interfere with the TGF-beta/Smad signaling pathway in a ligand-specific manner. Oncogene 22: 8212-20

Poncelet AC, Schnaper HW, Tan R, Liu Y, Runyan CE (2007) Cell phenotype-specific down-regulation of Smad3 involves decreased gene activation as well as protein degradation. J Biol Chem 282: 15534-40

Reizis, B. (2019) Plasmacytoid Dendritic Cells: Development, Regulation, and Function. Immunity 50: 37-50

Riedl E, Strobl H, Majdic O, Knapp W (1997) TGF-beta 1 promotes in vitro generation of dendritic cells by protecting progenitor cells from apoptosis. J Immunol 158: 1591-7

Robertson IB, Rifkin DB (2016) Regulation of the Bioavailability of TGF-beta and TGFbeta-Related Proteins. Cold Spring Harb Perspect Biol 8

Rojas A, Zhang P, Wang Y, Foo WC, Munoz NM, Xiao L, Wang J, Gores GJ, Hung MC, Blechacz B (2016) A Positive TGF-beta/c-KIT Feedback Loop Drives Tumor Progression in Advanced Primary Liver Cancer. Neoplasia 18: 371-86

Sanjabi S, Oh SA, Li MO (2017) Regulation of the Immune Response by TGF-beta: From Conception to Autoimmunity and Infection. Cold Spring Harb Perspect Biol 9 
YOON et al

Sarenac T, Trapecar M, Gradisnik L, Rupnik MS, Pahor D (2016) Single-cell analysis reveals IGF-1 potentiation of inhibition of the TGF-beta/Smad pathway of fibrosis in human keratocytes in vitro. Sci Rep 6: 34373

Schaper F, Siewert E, Gomez-Lechon MJ, Gatsios P, Sachs M, Birchmeier W, Heinrich PC, Castell J (1997) Hepatocyte growth factor/scatter factor (HGF/SF) signals via the STAT3/APRF transcription factor in human hepatoma cells and hepatocytes. FEBS Lett 405: 99-103

Schlitzer A, Sivakamasundari V, Chen J, Sumatoh HR, Schreuder J, Lum J, Malleret B, Zhang S, Larbi A, Zolezzi F, Renia L, Poidinger M, Naik S, Newell EW, Robson P, Ginhoux F (2015) Identification of cDC1- and cDC2-committed DC progenitors reveals early lineage priming at the common DC progenitor stage in the bone marrow. Nat Immunol 16: 718-28

Schotte R, Rissoan MC, Bendriss-Vermare N, Bridon JM, Duhen T, Weijer K, Briele F, Spits H (2003) The transcription factor Spi-B is expressed in plasmacytoid DC precursors and inhibits T-, B-, and NK-cell development. Blood 101: 1015-23.

Schotte R, Nagasawa M, Weijer K, Spits H, Blom B (2004) The ETS transcription factor SpiB is required for human plasmacytoid dendritic cell development. J Exp Med 200: 1503-09.

Schraml BU, Reis e Sousa C (2015) Defining dendritic cells. Curr Opin Immunol 32: 13-20 
YOON et al

Schraml BU, van Blijswijk J, Zelenay S, Whitney PG, Filby A, Acton SE, Rogers NC, Moncaut N, Carvajal JJ, Reis e Sousa C (2013) Genetic tracing via DNGR-1 expression history defines dendritic cells as a hematopoietic lineage. Cell 154: 843-58

Seeger P, Musso T, Sozzani S (2015) The TGF-beta superfamily in dendritic cell biology. Cytokine Growth Factor Rev 26: 647-57

Sere KM, Lin Q, Felker P, Rehage N, Klisch T, Ortseifer I, Hieronymus T, Rose-John S, Zenke M (2012) Dendritic cell lineage commitment is instructed by distinct cytokine signals. Eur J Cell Biol 91: 515-23

Singbrant S, Wall M, Moody J, Karlsson G, Chalk AM, Liddicoat B, Russell MR, Walkley CR, Karlsson S (2014) The SKI proto-oncogene enhances the in vivo repopulation of hematopoietic stem cells and causes myeloproliferative disease. Haematologica 99: 647-55

Soderberg SS, Karlsson G, Karlsson S (2009) Complex and context dependent regulation of hematopoiesis by TGF-beta superfamily signaling. Ann N Y Acad Sci 1176: 55-69

Strobl H, Riedl E, Scheinecker C, Bello-Fernandez C, Pickl WF, Rappersberger K, Majdic O, Knapp W (1996) TGF-beta 1 promotes in vitro development of dendritic cells from CD34+ hemopoietic progenitors. J Immunol 157: 1499-507

Suzuki H, Yagi K, Kondo M, Kato M, Miyazono K, Miyazawa K (2004) c-Ski inhibits the TGF-beta signaling pathway through stabilization of inactive Smad complexes on Smadbinding elements. Oncogene 23: 5068-76 
YOON et al

Takagi H, Fukaya T, Eizumi K, Sato Y, Sato K, Shibazaki A, Otsuka H, Hijikata A, Watanabe T, Ohara O, Kaisho T, Malissen B, Kaisho T (2011). Plasmacytoid dendritic cells are crucial for the initiation of inflammation and T cell immunity in vivo. Immunity 35: 95871.

Takeda M, Mizuide M, Oka M, Watabe T, Inoue H, Suzuki H, Fujita T, Imamura T, Miyazono K, Miyazawa K (2004) Interaction with Smad4 is indispensable for suppression of BMP signaling by c-Ski. Mol Biol Cell 15: 963-72

Wan CK, Oh J, Li P, West EE, Wong EA, Andraski AB, Spolski R, Yu ZX, He J, Kelsall BL, Leonard WJ (2013) The cytokines IL-21 and GM-CSF have opposing regulatory roles in the apoptosis of conventional dendritic cells. Immunity 38: 514-27

Waskow C, Liu K, Darrasse-Jeze G, Guermonprez P, Ginhoux F, Merad M, Shengelia T, Yao K, Nussenzweig M (2008) The receptor tyrosine kinase Flt3 is required for dendritic cell development in peripheral lymphoid tissues. Nat Immunol 9: 676-83

Wu JW, Krawitz AR, Chai J, Li W, Zhang F, Luo K, Shi Y (2002) Structural mechanism of Smad4 recognition by the nuclear oncoprotein Ski: insights on Ski-mediated repression of TGF-beta signaling. Cell 111: 357-67

Yamaguchi Y, Tsumura H, Miwa M, Inaba K (1997) Contrasting effects of TGF-beta 1 and TNF-alpha on the development of dendritic cells from progenitors in mouse bone marrow. Stem Cells 15: 144-53 
YOON et al

Yamazaki S, Iwama A, Takayanagi SI, Eto K, Ema H, Nakauchi H. (2009) TGF- $\beta$ as a candidate bone marrow niche signal to induce hematopoietic stem cell hibernation. Blood, 113: $1250-1256$

Yanagisawa K, Osada H, Masuda A, Kondo M, Saito T, Yatabe Y, Takagi K, Takahashi T, Takahashi T (1998) Induction of apoptosis by Smad3 and down-regulation of Smad3 expression in response to TGF-beta in human normal lung epithelial cells. Oncogene 17: $1743-7$

Yang X, Letterio JJ, Lechleider RJ, Chen L, Hayman R, Gu H, Roberts AB, Deng C (1999) Targeted disruption of SMAD3 results in impaired mucosal immunity and diminished T cell responsiveness to TGF-beta. EMBO J 18: 1280-91

Yoon JH, Sudo K, Kuroda M, Kato M, Lee IK, Han JS, Nakae S, Imamura T, Kim J, Ju JH, Kim DK, Matsuzaki K, Weinstein M, Matsumoto I, Sumida T, Mamura M (2015) Phosphorylation status determines the opposing functions of Smad2/Smad3 as STAT3 cofactors in TH17 differentiation. Nat Commun 6: 7600

Zavadil J, Bottinger EP (2005) TGF-beta and epithelial-to-mesenchymal transitions. Oncogene 24: 5764-74

Zi Z, Chapnik DA, Liu X (2012) Dynamics of TGF- $\beta$ /Smad signaling. FEBS Letters, 586.14: 1921-1928. 
YOON et al

\section{Figure legends}

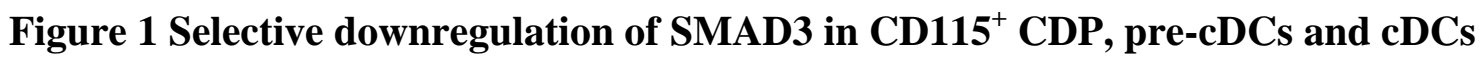
$\mathrm{LinCD}^{-} 117^{\mathrm{hi}} \mathrm{CD} 135^{+} \mathrm{CD} 115^{+} \mathrm{Sca}^{-}{ }^{-}(\mathrm{MDP}), \mathrm{LinC}^{-} \mathrm{CD} 117^{\mathrm{int}} \mathrm{CD} 135^{+} \mathrm{CD} 115^{+} \mathrm{CD} 127^{-}\left(\mathrm{CD} 115^{+}\right.$

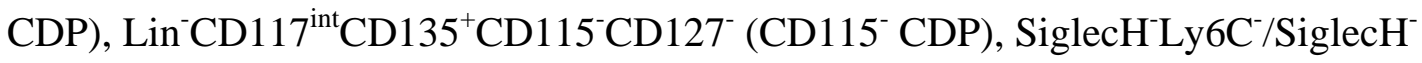
$\mathrm{Ly}_{6 \mathrm{C}}^{+} /$SiglecH $^{+} \mathrm{CD} 11 \mathrm{c}^{+} \mathrm{MHCII}^{-} \mathrm{CD} 135^{+} \mathrm{CD} 172 \alpha^{-}$(pre-cDC1/ pre-cDC2/ pre-pDC), bone marrow (BM) CD11 ${ }^{\text {hi }}$ CD $11 b^{+}$cDCs, BM CD11 $c^{+}$PDCA- ${ }^{+}$pDCs, FLT3L-induced BMDCs, GM-CSF plus IL-4-induced BMDCs, splenic CD11 $\mathrm{c}^{\mathrm{hi}} \mathrm{CD} 11 \mathrm{~b}^{+} \mathrm{cDCs}$, splenic PDCA- $1^{+} \mathrm{pDCs}$ were sorted using MACS system and/or FACSAria III.

(A) Expression of SMAD2 and SMAD3 mRNA was measured by quantitative RT-PCR. (B) Expression of SMAD2, C-terminally phosphorylated (p) SMAD2, SMAD3 and C-terminally pSMAD3 was measured by proximity ligation assay (PLA). Nucleus was stained with DAPI. CD11c, CD11b and PDCA-1 were stained with Alexa Fluor 488 (green) or 633 (yellow). Red dots in the nucleus (black) and cytoplasm (white) in 10 fields were quantified. Scale bars represent $10 \mu \mathrm{m}$. Data are representative of five independent experiments. Graphs show means + s.d. $P$ values were calculated by 2 -tailed unpaired Student's $t$ test. ** $P<0.01$ and *** $P<0.0005$.

\section{Figure 2. SMAD3 induces pDC, while it inhibits cDC differentiation}

FLT3L-induced BMDCs were transfected with SMAD3 DNA, control pcDNA or SMAD3 siRNA, control siRNA 4 hours prior to culture and analyzed on day 7.

(A) Contour plots show the expression of CD115 and CD135 on $\mathrm{Lin}^{-} \mathrm{Sca}-1^{-} \mathrm{CD} 117^{\mathrm{hi}}$ or $^{\mathrm{Lin}}{ }^{-}$ Sca- $1^{-} \mathrm{CD} 117^{\text {int }}$ cells.

(B) Contour plots show the expression of CD11c/MHCII, CD11b/CD24 and B220/PDCA-1 in $\mathrm{CD} 11 \mathrm{c}^{+}$gate. 
YOON et al

(C) May-Grunwald/Giemsa stained FLT3L-induced BMDCs transfected with SMAD3 DNA, SMAD3 siRNA or control pcDNA. Scale bars represent $50 \mu \mathrm{m}$.

(D) Contour plots show the expression of CD11c/MHCII, CD11b/CD24 and B220/PDCA-1 in $\mathrm{CD} 11 \mathrm{c}^{+}$gate of $\mathrm{Smad3}^{+/+}$or $\mathrm{Smad}^{-/-}$FLT3L-induced BMDCs treated with or without TGF- $\beta 1$ (5 ng/ml) or Activin A (10 ng/ml).

Data are representative of three independent experiments.

\section{Figure 3. Lack of pDC with increase of $\mathrm{cDC}$ in $\mathrm{Smad3}^{-/-}$mice}

Immunophenotyping of $\operatorname{Smad}^{-/-}$or $\mathrm{Smad}^{+/+}$mice $(\mathrm{n}=6$ /genotype) was performed using flowcytometry.

(A) Contour plots show the expression of CD115/CD135 in $\mathrm{Lin}^{-} \mathrm{Sca}-1^{-} \mathrm{CD} 117^{\mathrm{hi}}$ or $\mathrm{Lin}^{-} \mathrm{Sca}-1^{-}$ $\mathrm{CD} 117^{\text {int }}$ gates. Graphs show the cell numbers of $\mathrm{Lin}^{-} \mathrm{CD} 117^{\mathrm{hi}} \mathrm{CD} 115^{+} \mathrm{CD} 135^{+} \mathrm{MDP}$ and $\mathrm{Lin}^{-}$ $\mathrm{CD} 117^{\text {int }} \mathrm{CD} 115^{+} \mathrm{CD} 135^{+} \mathrm{CDP}$ in $\mathrm{BM}$.

(B) Quantitative RT-PCR of Cx3crl and Dngrl mRNA in Lin ${ }^{-C D} 115^{+}$BM cells and contour plots of CX3CR $1^{+} \mathrm{CD} 370^{+} \mathrm{Lin}^{-} \mathrm{CD} 117^{\text {int }} \mathrm{CD} 115^{+} \mathrm{CD} 135^{+} \mathrm{BM}$ cells.

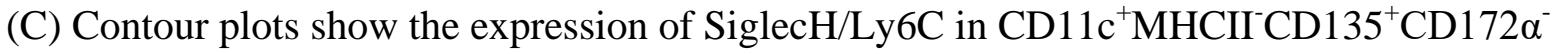
pre-DC gate. Graphs show the cell numbers in BM.

(D) Contour plots show the expression of CD11c, MHCII, CD11b, CD8, SiglecH, PDCA-1 and B220 in BM, spleen, superficial and mesenteric lymph nodes. Graphs show the cell numbers of $\mathrm{CD} 11 \mathrm{~b}^{+}, \mathrm{CD}^{+}$, SiglecH $\mathrm{HDCA}^{+} 1^{+} \mathrm{B} 220^{+}$cells in $\mathrm{CD} 11 \mathrm{c}^{+}$gate.

Graphs show means \pm s.d. $P$ values were calculated by 2 -tailed unpaired Student's $t$ test.

Figure 4. SMAD3 represses cDC-related genes while induces pDC-related genes Expressions of Siglech, Bst2, Spib, E2-2, Ikaros, Flt3, Id2 and Irf4 mRNA in (A) MDP, CD115 ${ }^{+}$CDP, CD115 CDP, pre-cDC1/ pre-cDC2/ pre-pDC, BM CD11 $c^{\text {hi }}$ cDCs, BM pDCs, 
YOON et al

FLT3L-induced BMDCs, GM-CSF plus IL-4-induced BMDCs, splenic cDCs, splenic pDCs from $\mathrm{Smad}^{-/-}$or $\mathrm{Smad3}^{+/+}$mice.

Expressions of Siglech, Bst2, Spib, E2-2, Ikaros mRNA in (B) FLT3L-induced BMDCs transfected with SMAD3 DNA or control pcDNA 4 hours prior to culture and analyzed on day 2, 4, 6, 8 and in (C) $\operatorname{Smad}^{-/-}$or $\operatorname{Smad}^{+/+}$FLT3L-induced BMDCs treated with the indicated concentrations of TGF- $\beta 1$ on day 8 were determined by quantitative RT-PCR. Expressions of Flt3, Id2 and Irf4 mRNA in (D) FLT3L-induced BMDCs transfected with SMAD3 DNA or control pcDNA 4 hours prior to culture on day 2, 3, 4, 6, 8 and in (E) $\mathrm{Smad3}^{-/-}$or Smad3 ${ }^{+/+}$FLT3L-induced BMDCs treated with the indicated concentrations of TGF- $\beta 1$ on day 8 were determined by quantitative RT-PCR.

Data are representative of three independent experiments with triplicate. Graphs show means \pm s.d. $P$ values were calculated by 2 -tailed unpaired Student's $t$ test. $* P<0.05$, ** $P<0.01$ and *** $P<0.0005$.

\section{Figure 5. TGF- $\beta$ induces transcription of the $S m a d 3$ gene, thereby pDC differentiation}

Contour plots show the expressions of CD11b/PDCA-1 in CD11 $\mathrm{c}^{+}$gate of (A) FLT3Linduced BMDCs and (B) GM-CSF plus IL-4-induced BMDCs from Smad37-/ or $\mathrm{Smad3}^{+/+}$ mice treated with the indicated concentrations of TGF- $\beta 1$. Data are representative of three independent experiments.

(C) Expressions of SMAD3 and C-terminally pSMAD3 in FLT3L-induced BMDCs treated with the indicated concentrations of TGF- $\beta 1$ were determined by PLA (red). Nucleus was stained with DAPI. CD11c was stained with Alexa Fluor 488. PDCA-1 was stained with Alexa Fluor 633. Red dots in the nucleus (black) and cytoplasm (white) in 10 fields were quantified. Scale bars represent $10 \mu \mathrm{m}$. 
YOON et al

(D) Smad3 promoter activity was determined using FLT3L-induced BMDCs transfected with the Smad3 promoter luciferase reporter construct treated with the indicated concentrations of TGF- $\beta 1$.

(E) Smad3 promoter activity was determined using PDCA- $1^{+}$FLT3L-induced BMDCs transfected with the Smad3 promoter luciferase reporter construct with the indicated combinations of SMAD2, SMAD3, SMAD4 and p300.

(F) Binding of SMAD2, SMAD3, SMAD4, p300 and the histone modification in the Smad3 proximal promoter region in PDCA- $1^{+}$FLT3L-induced BMDCs was determined by chromatin immunoprecipitation (ChIP) using the antibodies against SMAD2, SMAD3, SMAD4, p300, acetyl histone H3K23 (H3K23Ac), trimethyl histone H3K4 (H3K4me3) and trimethyl histone H3K27 (H3K27me3).

FLT3L-induced BMDCs were transfected with the Smad3 promoter luciferase reporter construct and the indicated DNA constructs 4 hours prior to culture and analyzed on day 7 . Data of the Smad3 promoter luciferase reporter assay and ChIP are representative of three to five independent experiments with triplicate. Graphs show means + s.d. $P$ values were calculated by 2 -tailed unpaired Student's $t$ test. $* * P<0.01$ and $* * * P<0.0005$.

\section{Figure 6. STAT3 and c-SKI repress transcription of SMAD3 for cDC differentiation}

(A) Expressions of Smad3 mRNA in FLT3L-induced BMDCs transfected with STAT3 DNA, control pcDNA or STAT3 siRNA were determined by quantitative RT-PCR.

Smad3 promoter activity was determined using CD11 ${ }^{+}$FLT3L-induced BMDCs transfected with the Smad3 promoter luciferase reporter construct with the indicated combinations of (B) SMAD2, SMAD3, SMAD4, STAT3 and c-SKI, (C) SMAD2, SMAD3, SMAD4, STAT3 and c-SKI siRNA, (D) SMAD2, SMAD3, STAT3 siRNA and c-SKI. 
YOON et al

(E) Binding of SMAD2, SMAD3, STAT3, c-SKI and the histone modification in the Smad3 proximal promoter region in CD11 $\mathrm{b}^{+} \mathrm{FLT} 3 \mathrm{~L}$-induced BMDCs was determined by ChIP using the antibodies against SMAD2, SMAD3, STAT3, c-SKI, H3K23Ac, H3K4me3 and H3K27me3. FLT3L-induced BMDCs were transfected with the Smad3 promoter luciferase reporter construct, the indicated siRNA and DNA constructs 4 hours prior to culture and analyzed on day 7. $P$ values were calculated by 2 -tailed unpaired Student's $t$ test. $* * P<0.01$ and $* * * P<0.0005$.

Figure 7. Interaction of phosphorylated STAT3 with c-SKI is essential for repression of SMAD3 in cDC.

Proximity between (A) SMAD2 and c-SKI, c-SKI and STAT3 in MDP, CD115 ${ }^{+}$CDP, BM CD11 ${ }^{\text {hi }}$ CD11 b ${ }^{+}$cDCs, CD115 CDP, BM pDCs, FLT3L-induced BMDCs, GM-CSF plus IL-4-induced BMDCs, splenic cDCs, (B) STAT3 and SMAD2, SMAD2 and c-SKI in FLT3L-induced or GM-CSF plus IL-4-induced BMDCs transfected with the indicated c-SKI siRNA, STAT3 siRNA or control siRNA was determined by PLA. Nucleus was stained with DAPI. CD11c was stained with Alexa Fluor 488 (green). Red dots in the nucleus (black) and cytoplasm (white) in 10 fields were quantified. Scale bars represent $10 \mu \mathrm{m}$. Data are representative of three independent experiments. Graphs show means + s.d.

(C) Effects of c-SKI mutations $(\Delta 2 / 3$ that does not interact with Smad2/3 and W274E that does not interact with Smad4) on Smad3 promoter activity in CD11b ${ }^{+}$FLT3L-induced BMDCs were determined by the $S m a d 3$ promoter luciferase reporter assay.

(D) Contour plots show the expression of CD11c/MHCII in CD11 ${ }^{+}$gate of FLT3L-induced BMDCs transfected with the indicated c-SKI mutants, c-SKI siRNA or control pcDNA, control siRNA. 
YOON et al

(E) Effects of STAT3 phosphorylation site-specific mutants (Y705F and S727A) on

SMAD2/3-induced activation of the Smad3 promoter constructs transfected in FLT3L-

induced BMDCs were determined by the Smad3 promoter luciferase reporter assay.

(F) Contour plots show the expression of CD11c/MHCII in CD11 $\mathrm{b}^{+}$gate of FLT3L-induced BMDCs transfected with the indicated STAT3 phosphorylation site-specific mutants (Y705F and S727A) or STAT3 siRNA, control siRNA 4 hours prior to culture and analyzed on day 7. Data are representative of three independent experiments. Graphs show means + s.d. $P$ values were calculated by 2 -tailed unpaired Student's $t$ test. ** $P<0.01$ and *** $P<0.0005$. 
bioRxiv preprint doi: https://doi.org/10.1101/715060; this version posted July 25, 2019. The copyright holder for this preprint (which was not certified by peer review) is the author/funder. All rights reserved. No reuse allowed without permission.

\section{YOON et al}

\section{METHODS}

Detailed materials and methods are described in Supplemental Experimental Procedures. 
Figure 1. Yoon et al.

A

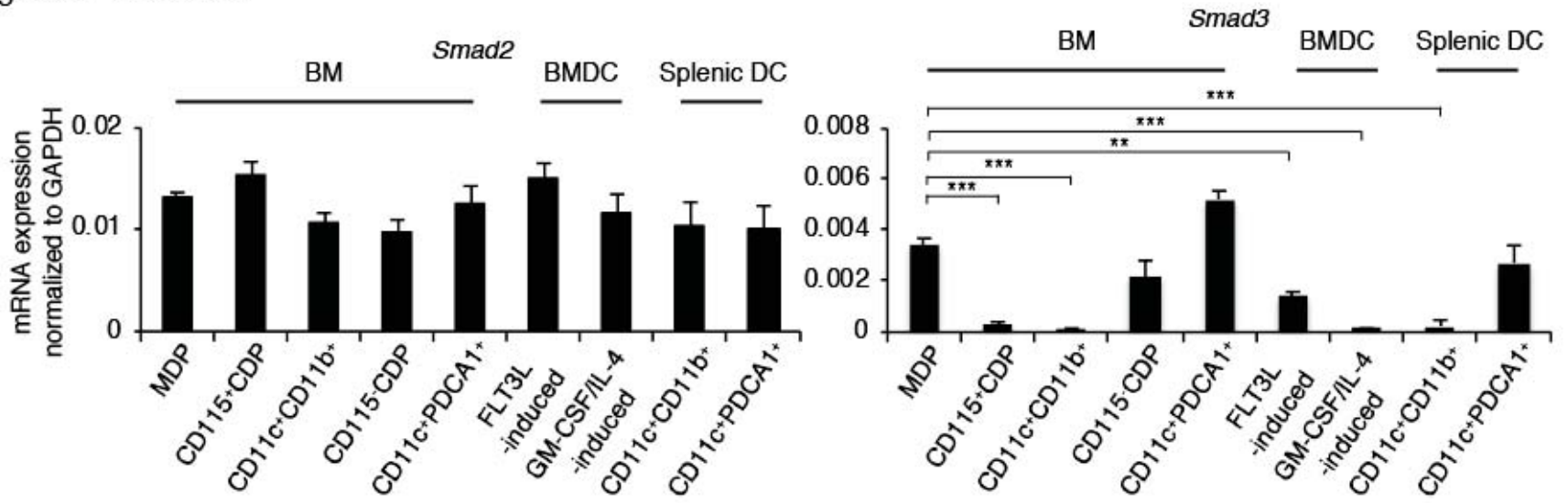

B

BM

BMDC

Splenic DC
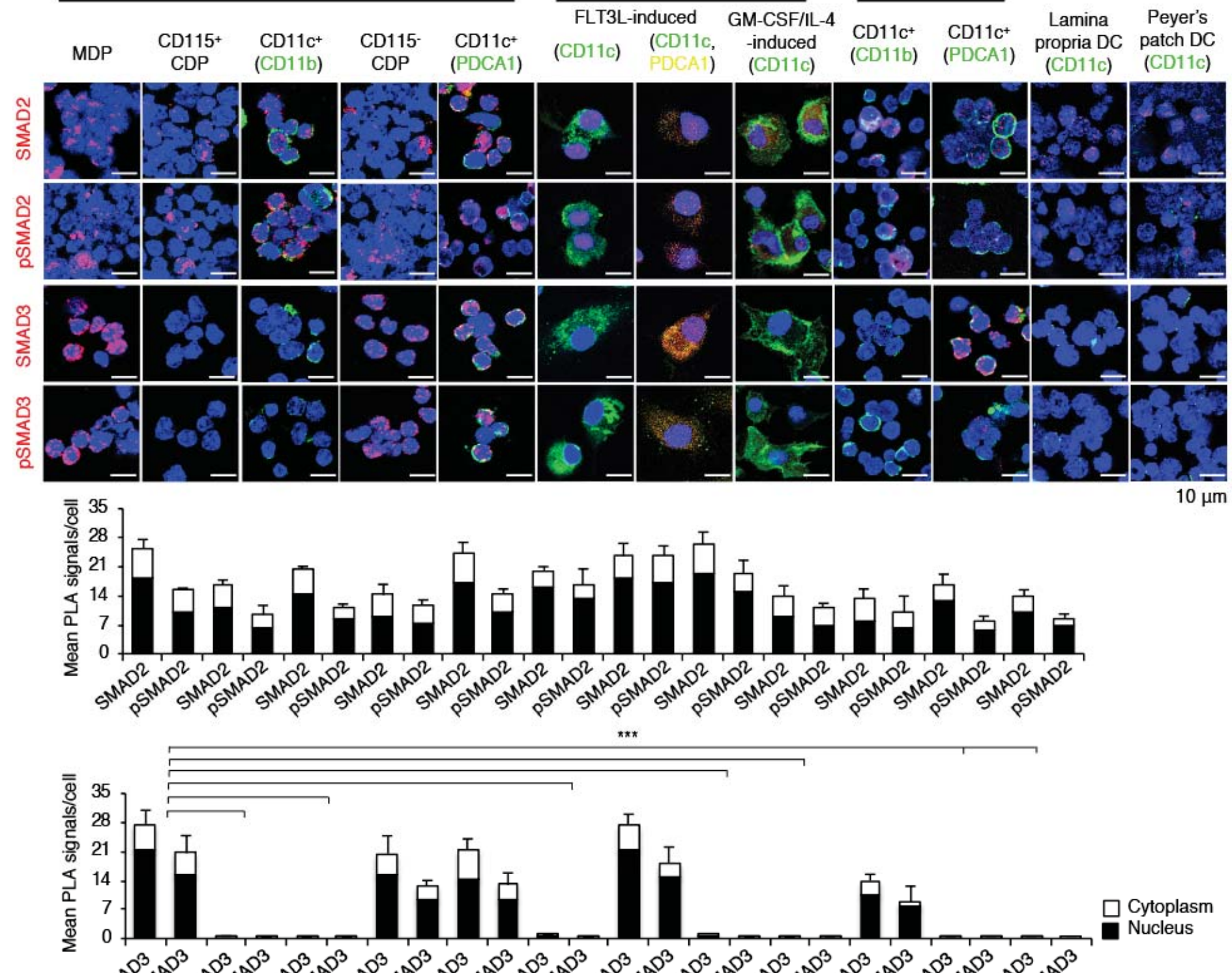

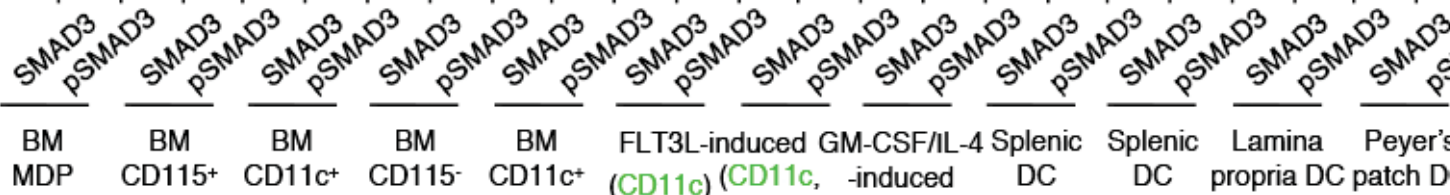
CDP (CD11b) CDP (PDCA1) 
Figure 2. Yoon et al.

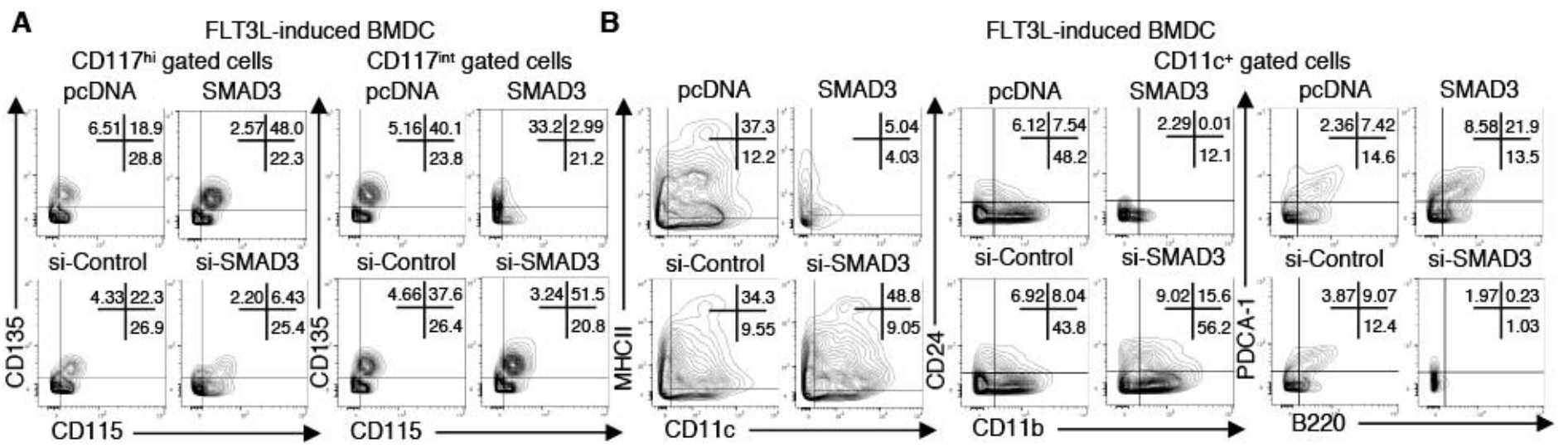

C

FLT3L-induced BMDC

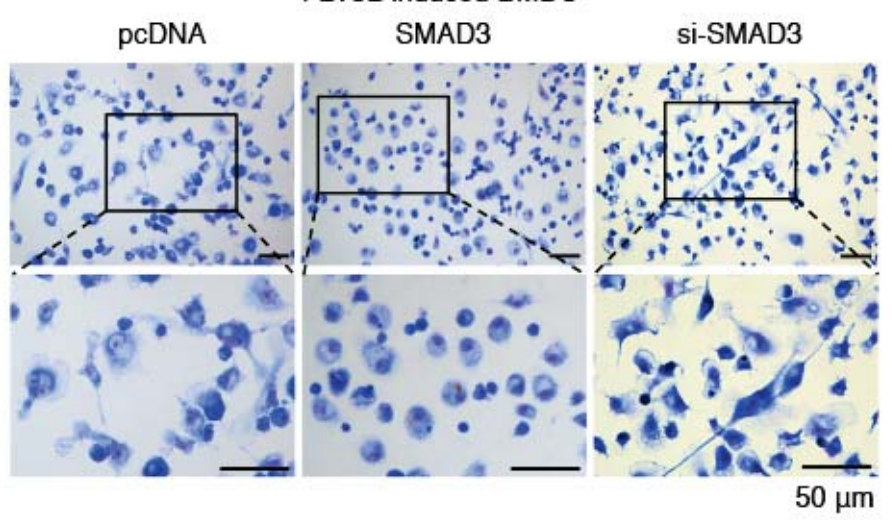

D

FLT3L-induced BMDC

$(-) \quad$ TGF- $\beta 1(+)$
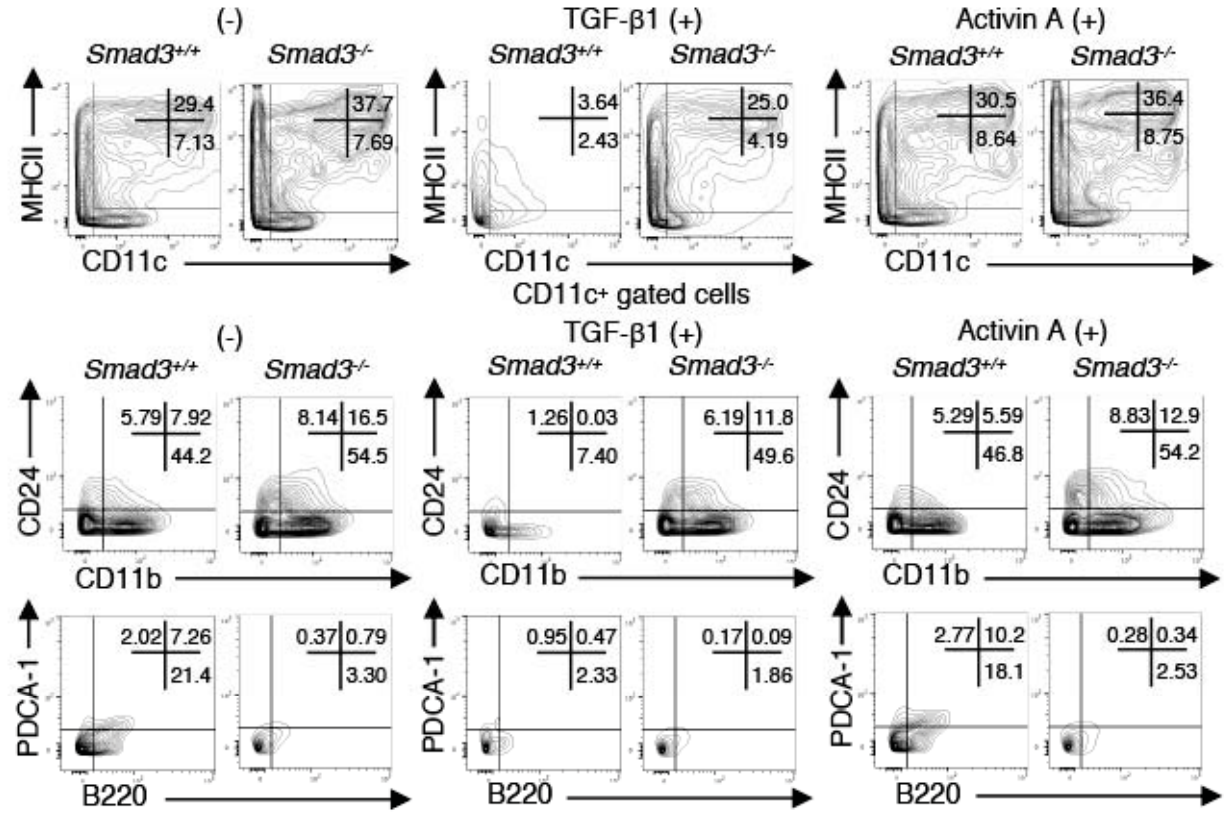
Figure 3. Yoon et al.

A Lin-CD117 ${ }^{\mathrm{hi}}$ gated BM cells

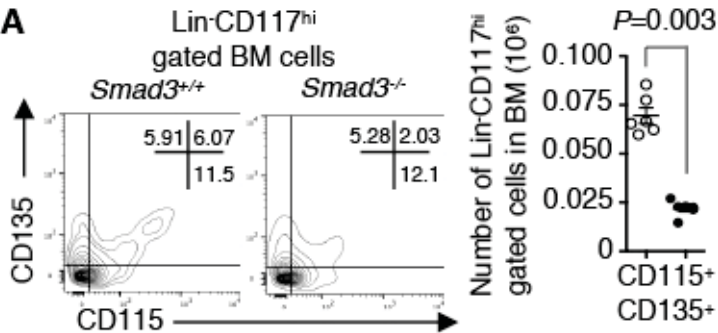

Lin-CD117int

gated BM cells

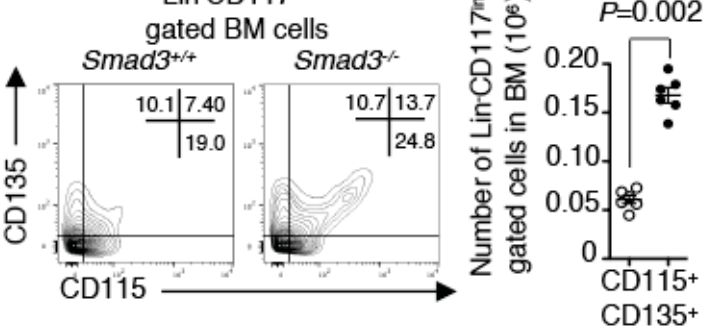

B

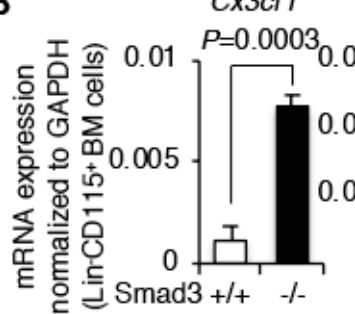

C

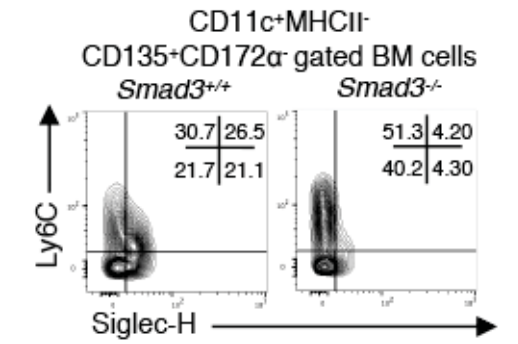

Dngr1 $P=0.0008$
Lin-CD117 ${ }^{\text {it }}$ CD115+CD135+ gated BM cells

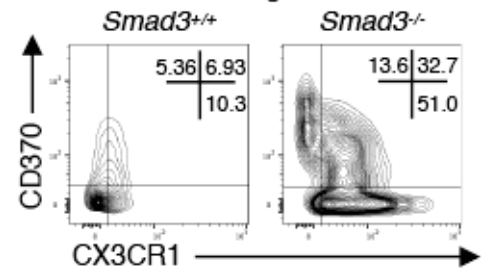

D

O $\mathrm{Smad}^{+/+} \bullet \mathrm{Smad}^{-/}$

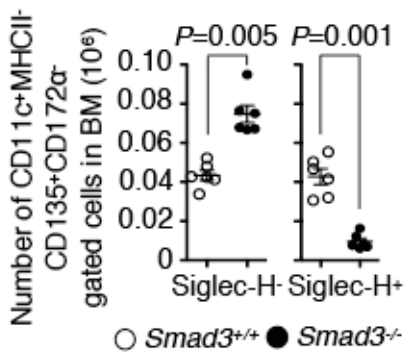

O Smad3 ${ }^{+/+}$Smad $3^{-/}$
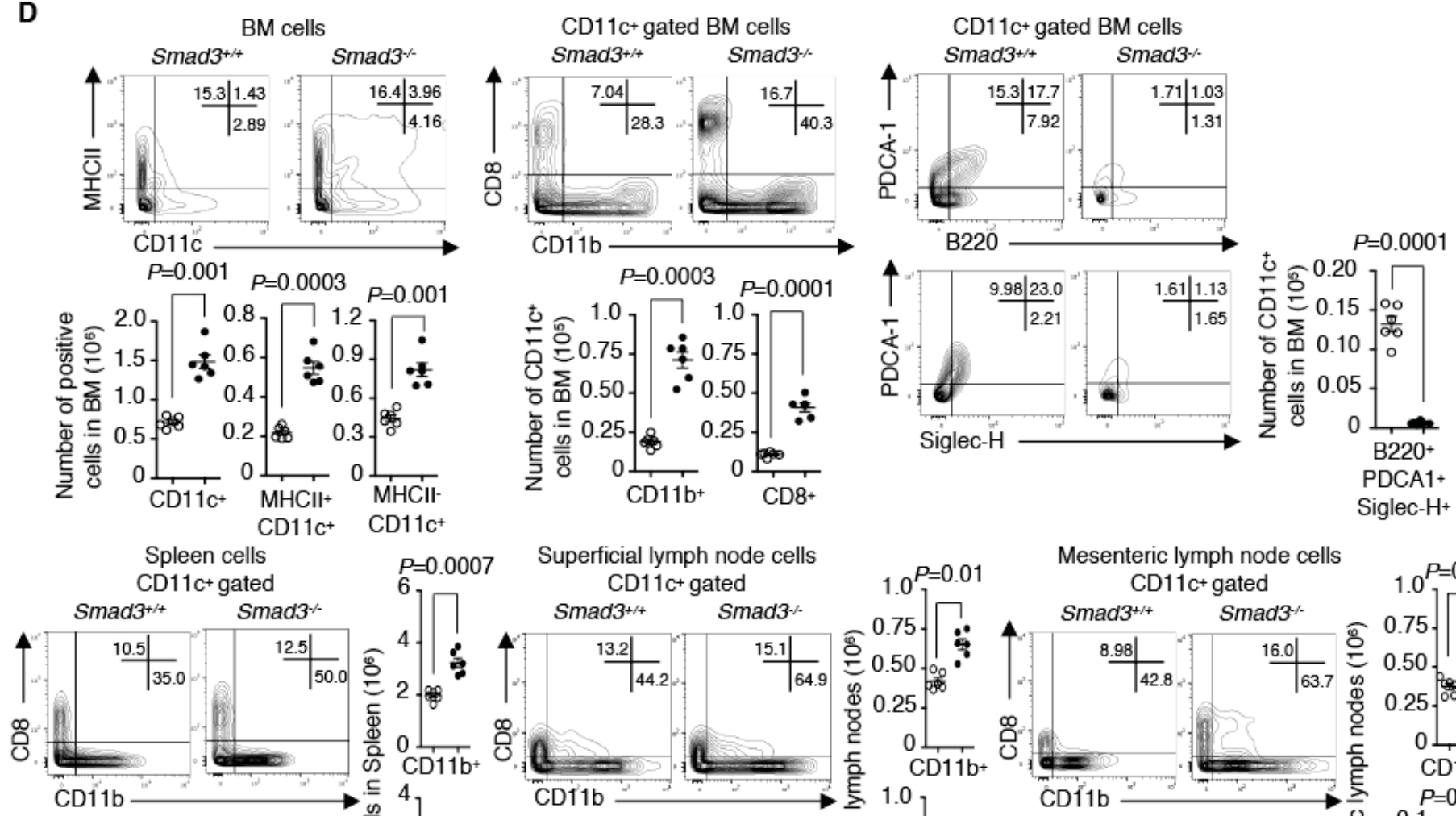

7 Superficial lymph node cells
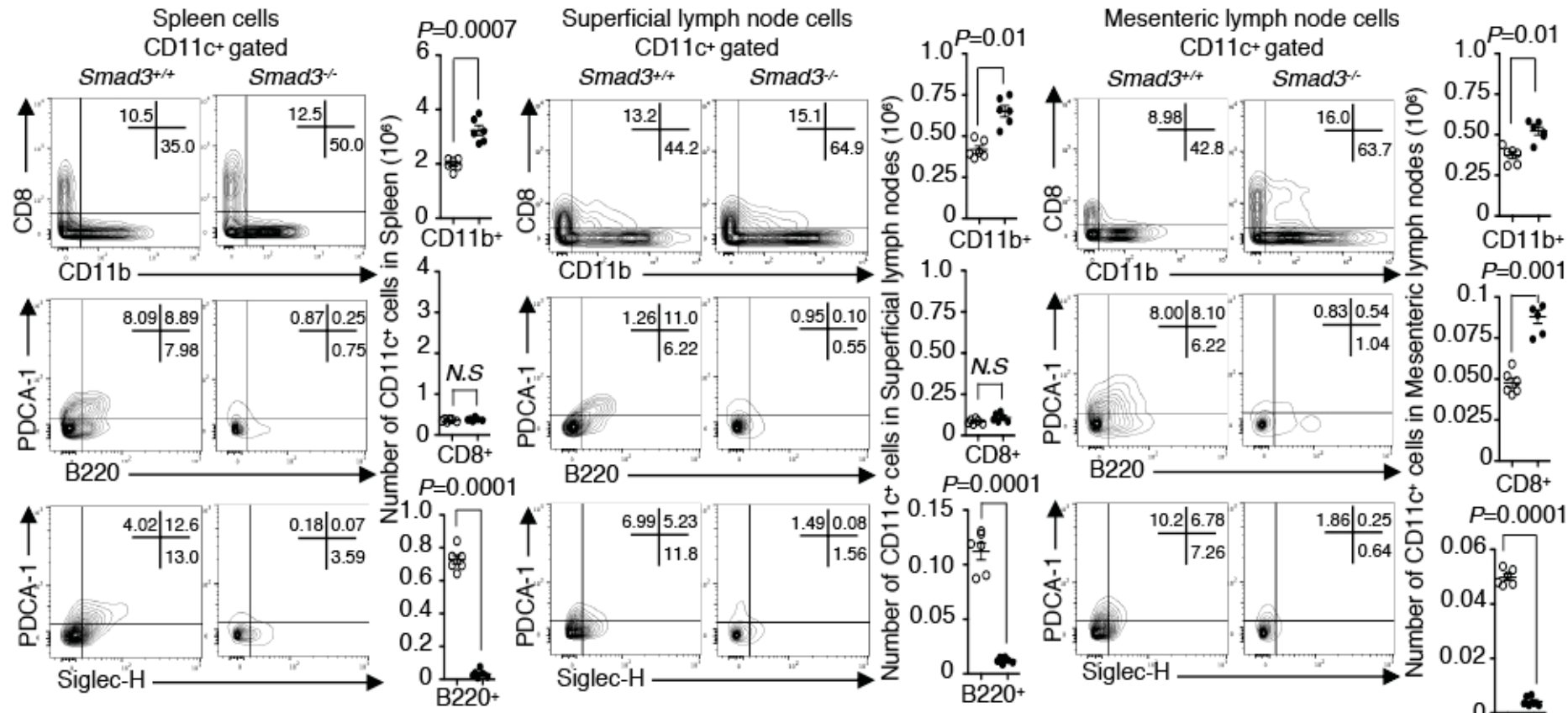

PDCA1+

Siglec- $\mathrm{H}$
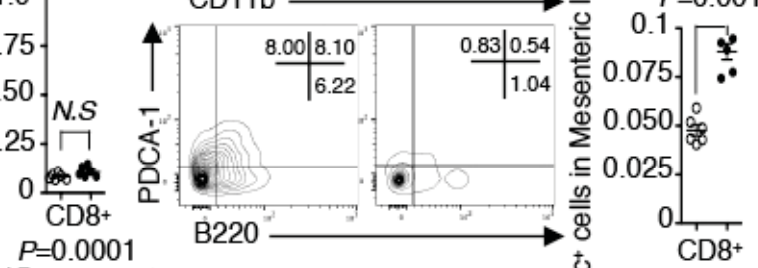

Siglec- $\mathrm{H}^{+}$

O $\mathrm{Smad}^{+/+} \bullet \mathrm{Smad3}^{-}$
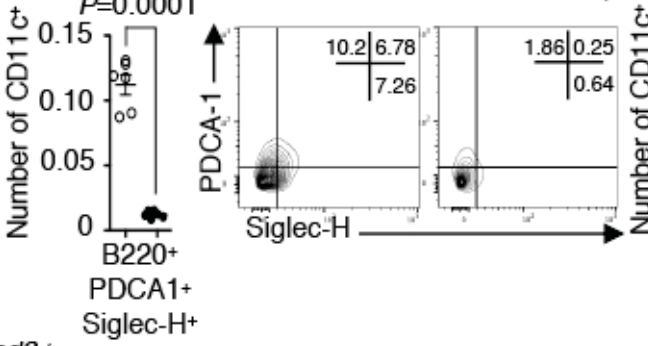

CD8+

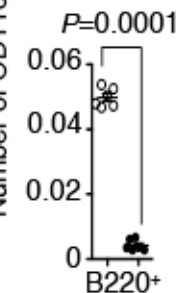

PDCA1+

Siglec- $\mathrm{H}^{+}$ 
Figure 4. Yoon et al.

A

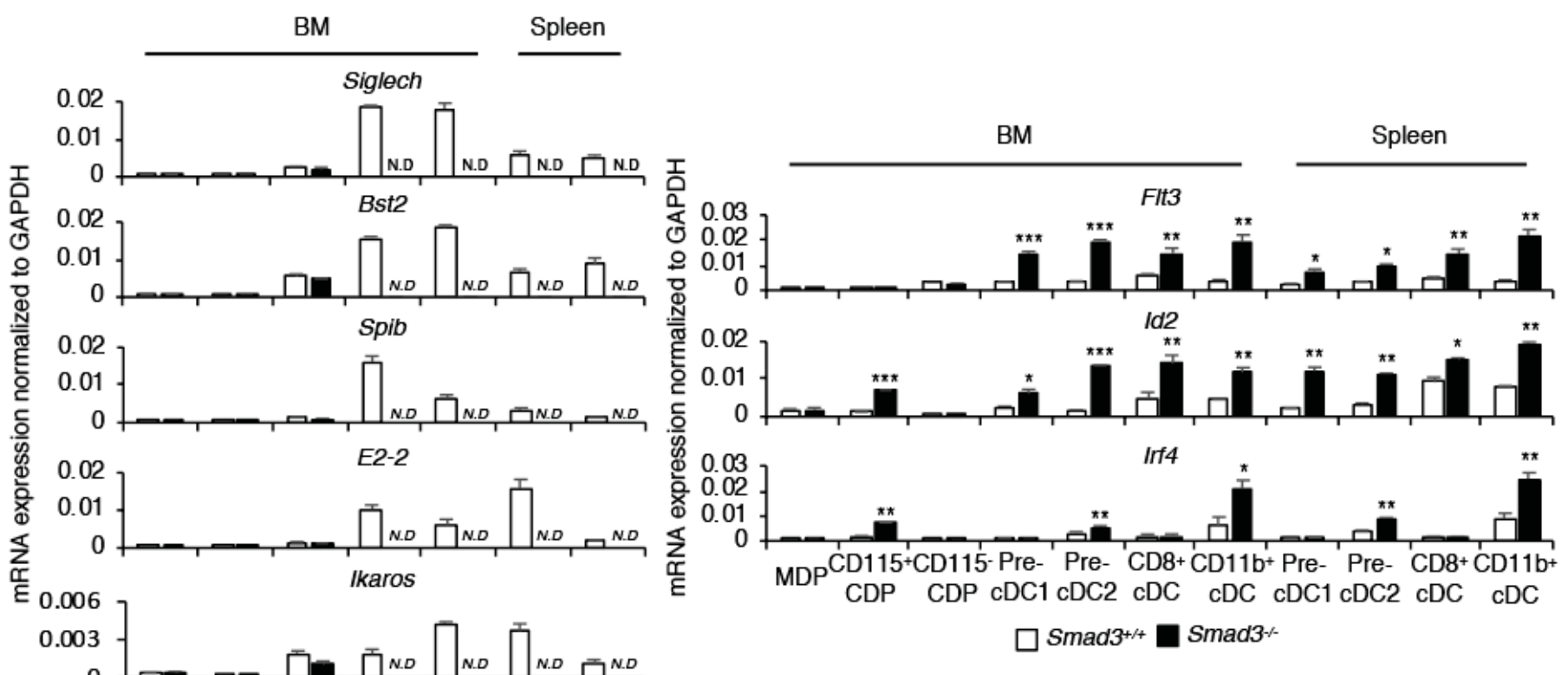

B

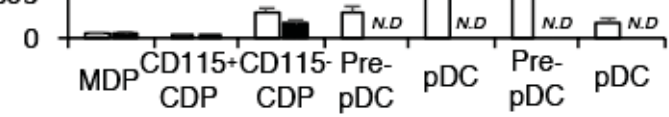

FLT3L-induced BMDC
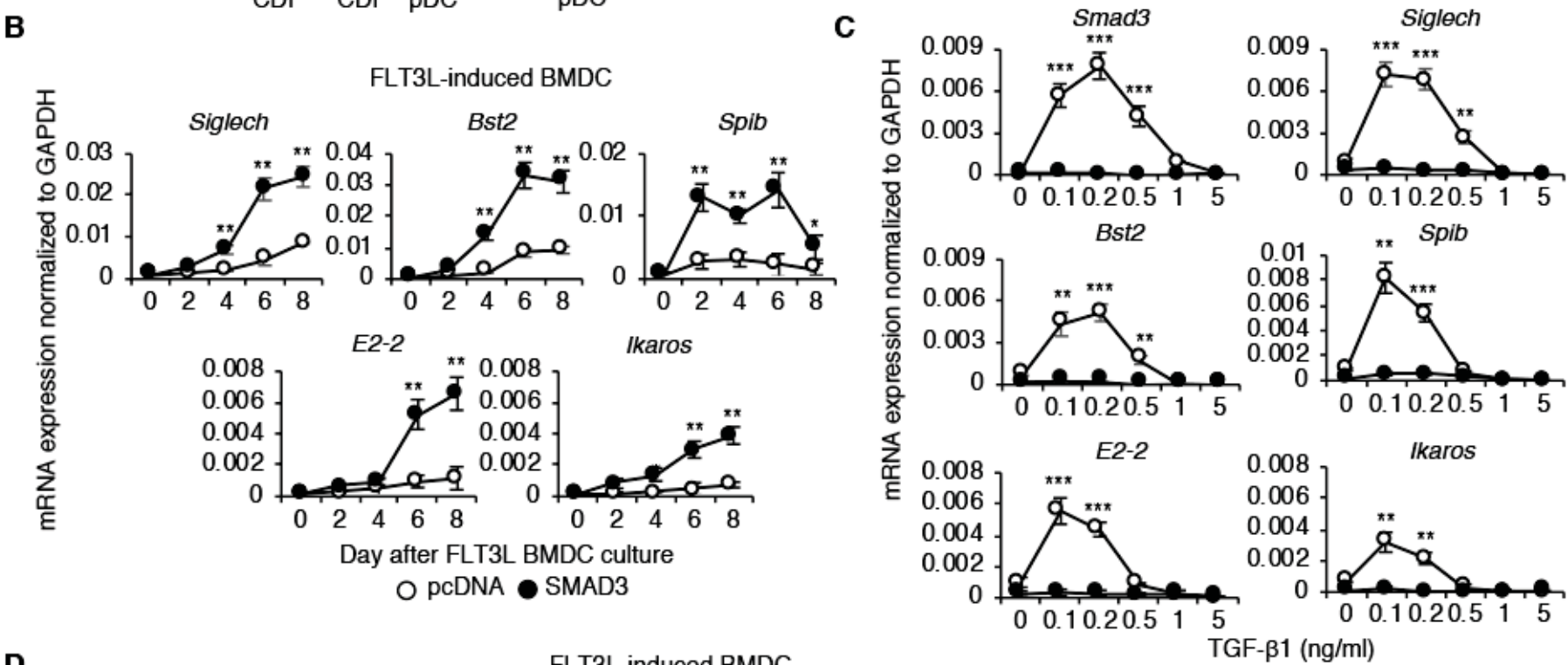

D

FLT3L-induced BMDC
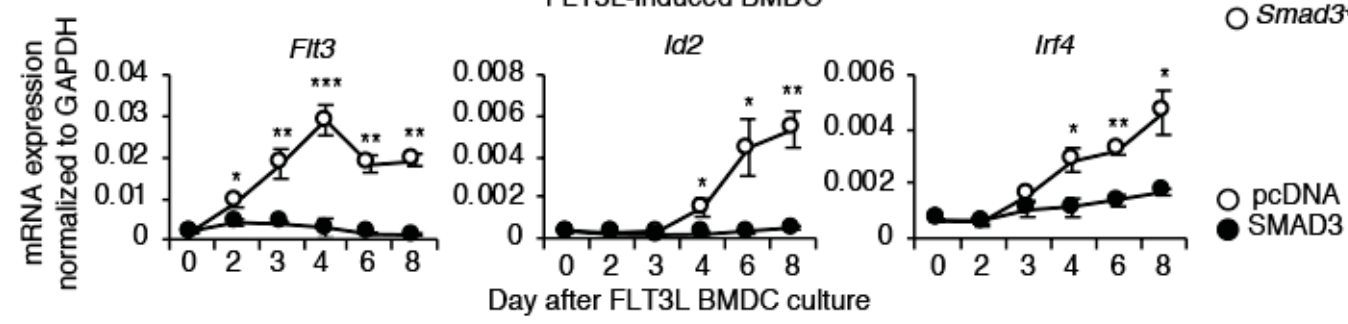

E

FLT3L-induced BMDC

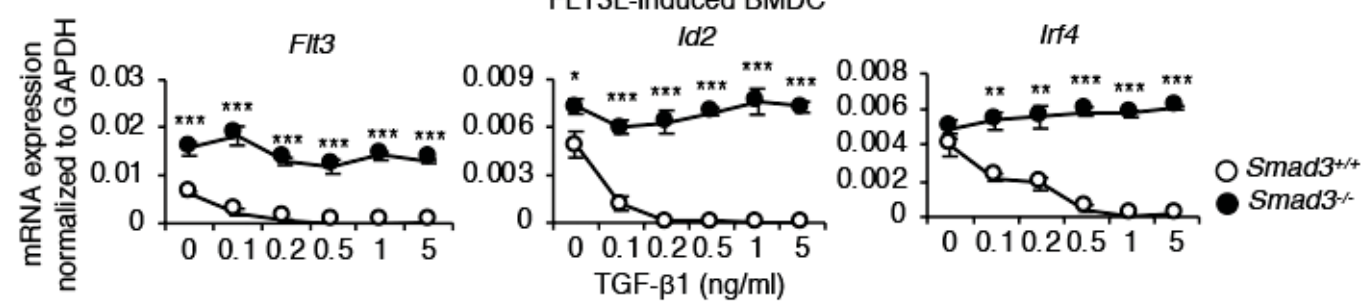


Figure 5. Yoon et al.

A

FLT3L-induced BMDC

TGF- $\beta 1$ (ng/ml)

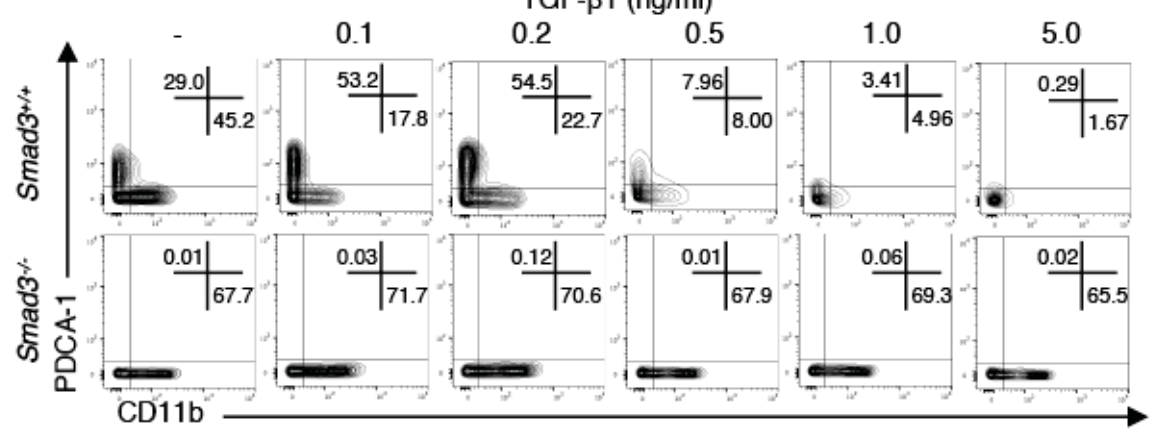

B

GM-CSF/IL-4-induced BMDC

TGF- $\beta 1$ (ng/ml)

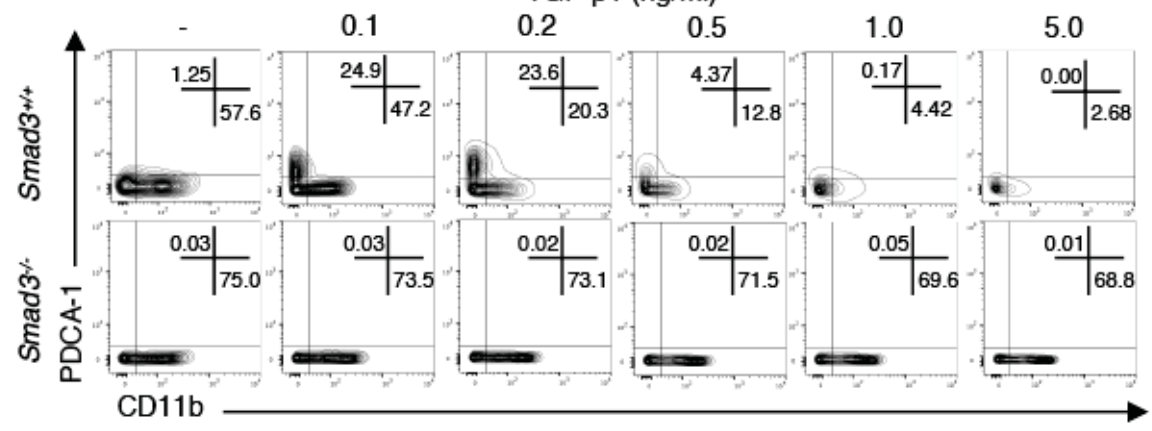

C

FLT3L-induced BMDC

TGF- $\beta 1$ (ng/ml)

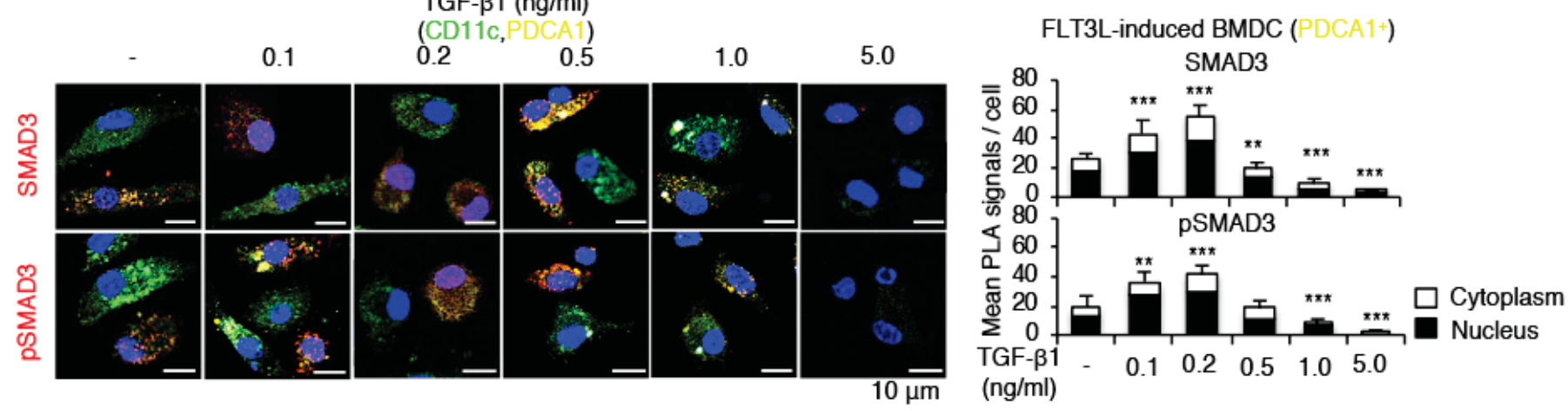

D

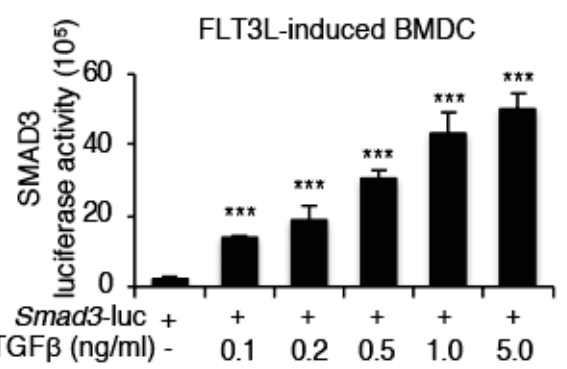

$\mathbf{F}$

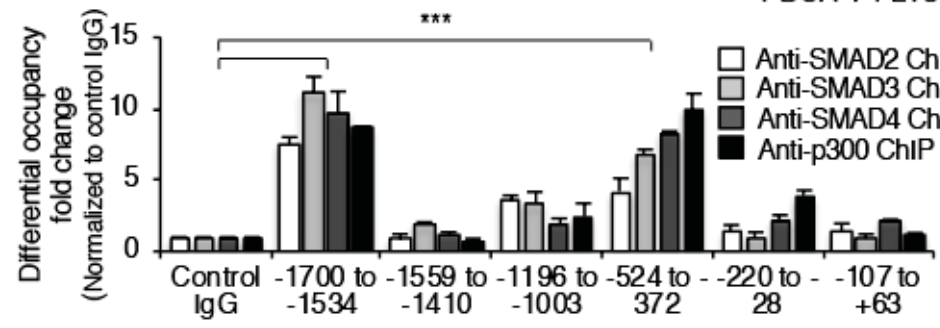

E

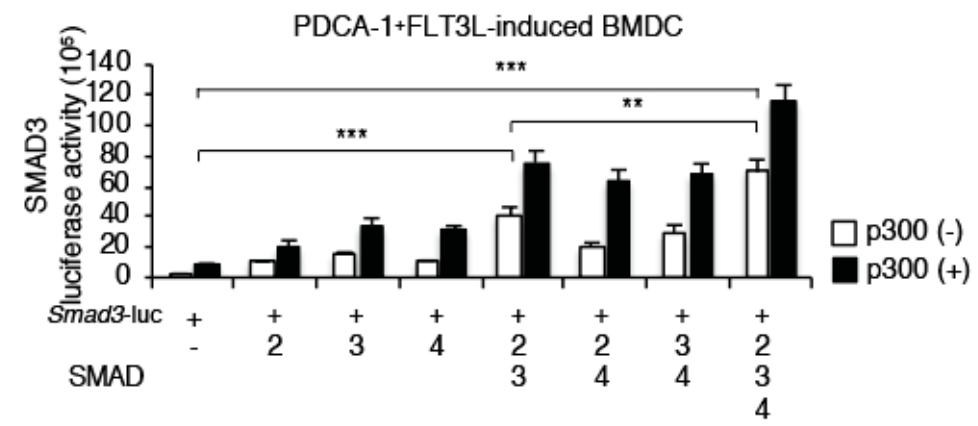

PDCA-1+FLT3L-induced BMDC

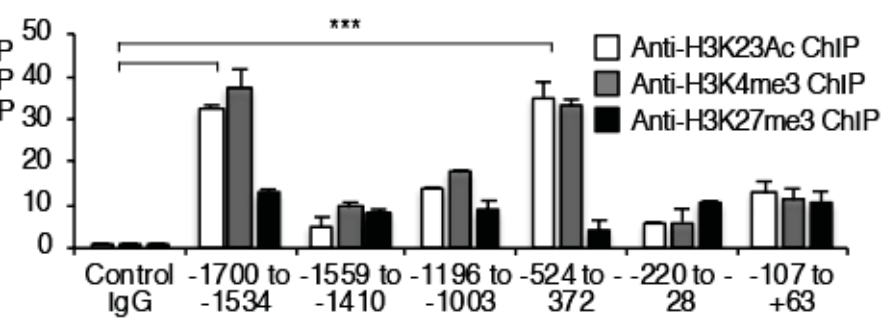


Figure 6. Yoon et al.

A

FLT3L-induced BMDC

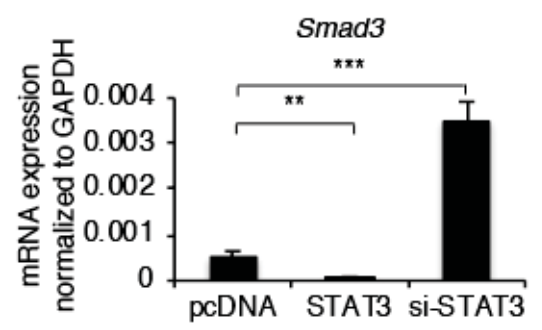

B

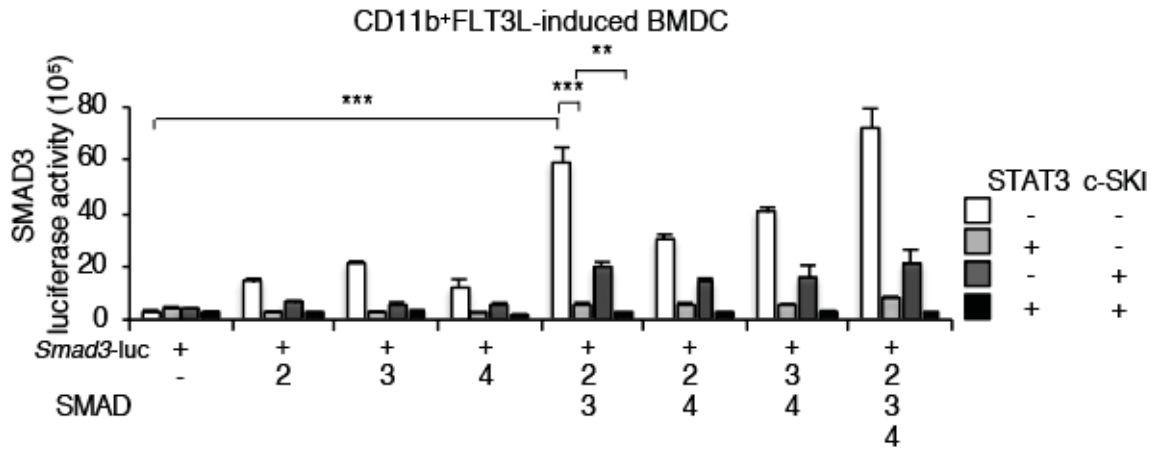

C

CD11b+FLT3L-induced BMDC

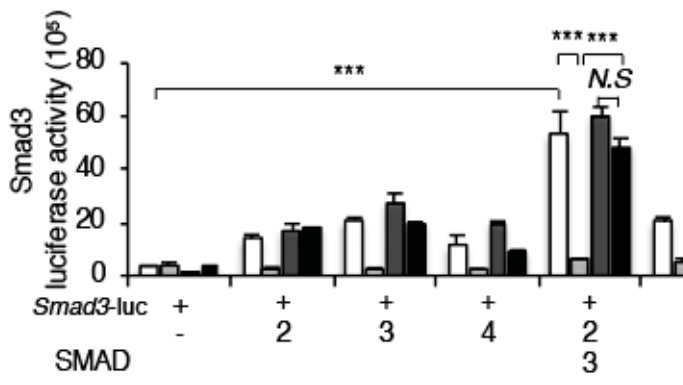

E

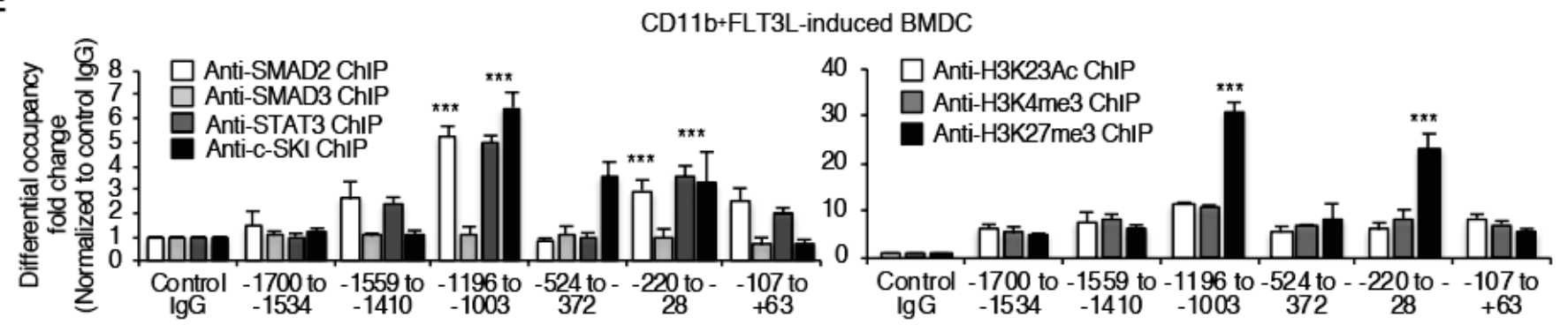

D

CD11b+FLT3L-induced BMDC

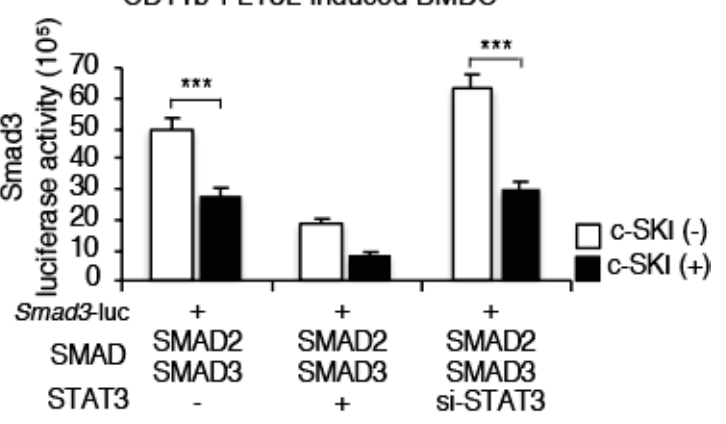


A

Figure 7. Yoon et al.

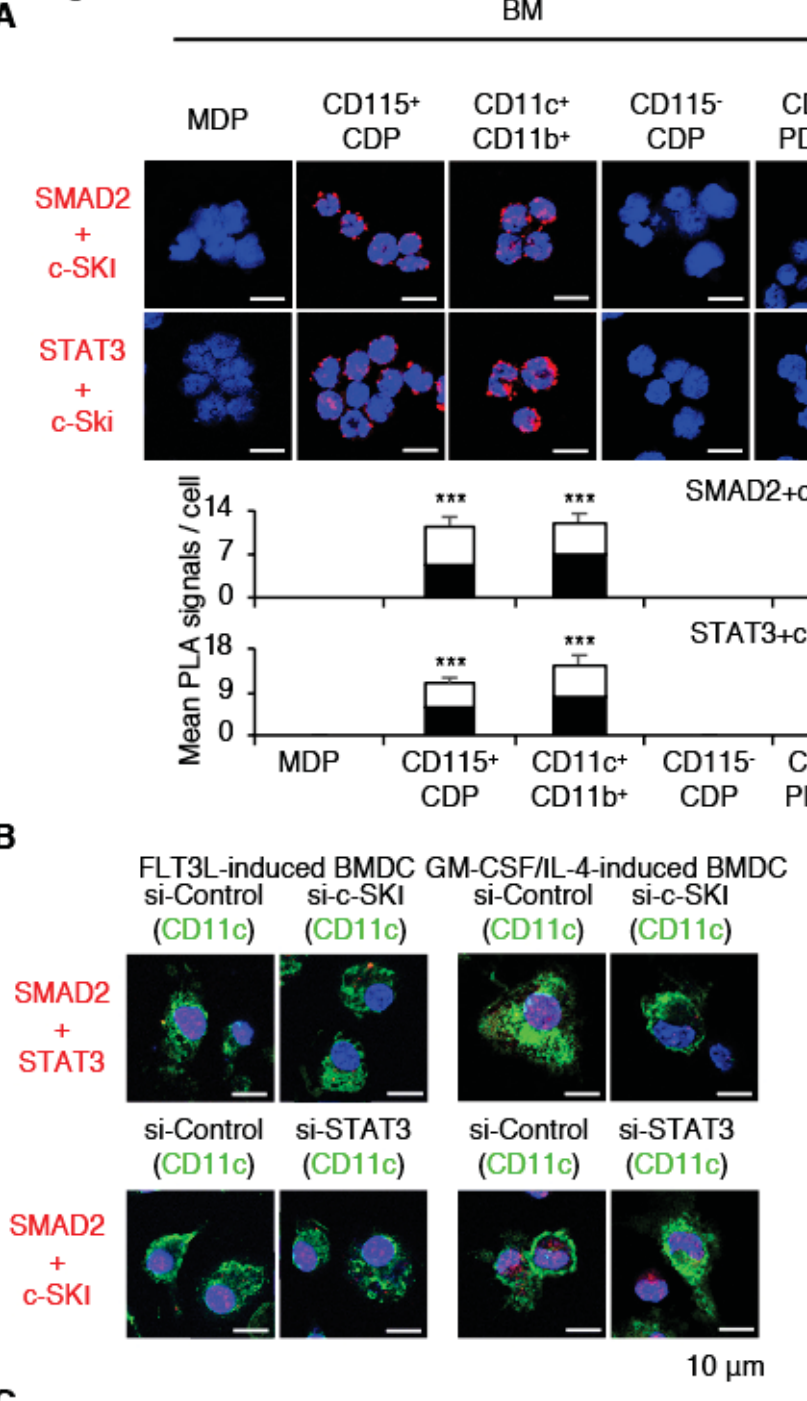

C

CD11b+FLT3L-induced BMDC

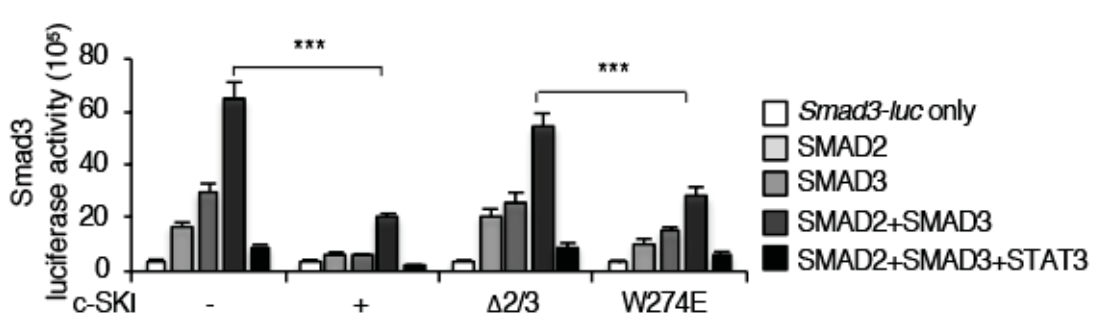

E

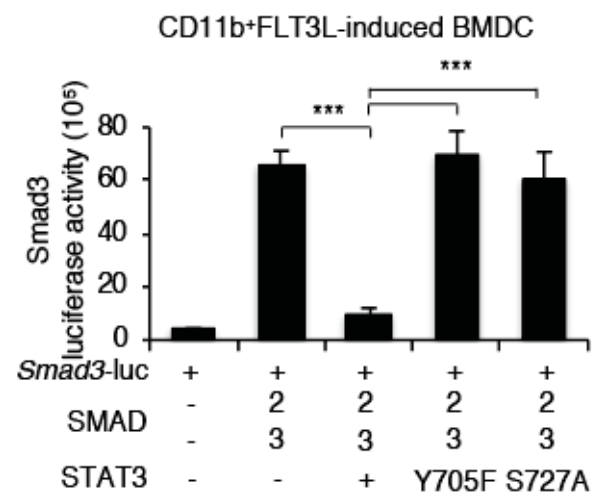

BMDC Splenic DC

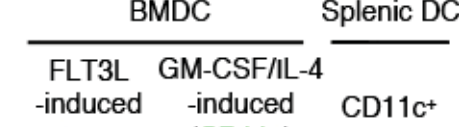

(CD11c) (CD11c) (CD11c)

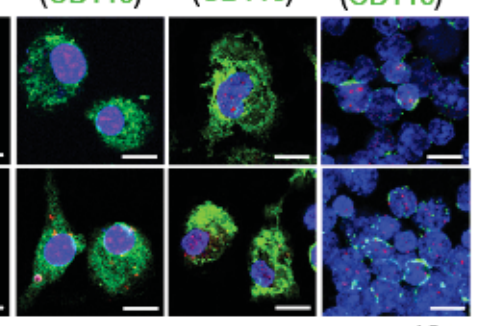

$10 \mu \mathrm{m}$

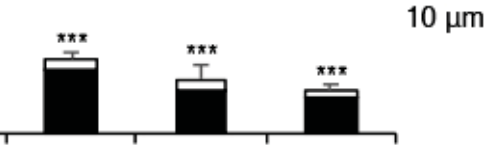

